\title{
THE INFLUENCE OF THE MODULUS- DENSITY RELATIONSHIP AND THE MATERIAL MAPPING METHOD ON THE SIMULATED MECHANICAL RESPONSE OF THE PROXIMAL FEMUR IN SIDE-WAYS FALL LOADING CONFIGURATION
}

\section{B. Helgason ${ }^{*, 1}$, S. Gilchrist ${ }^{3,4,5,6}$, O. Ariza ${ }^{1,3,4,5}$, P. $\operatorname{Vogt}^{1}$, W. Enns-Bray $^{1}$, R. P. Widmer ${ }^{1}$, T. Fitze ${ }^{2}$, H. Pálsson ${ }^{7}$, Y. Pauchard $^{2}$, P. Guy ${ }^{4,6}$ S. J. Ferguson ${ }^{1}$, and P. A. Cripton ${ }^{3,4,5,6}$}

\author{
${ }^{1}$ Institute for Biomechanics, \\ ETH-Zürich, Switzerland. \\ ${ }^{2}$ Institute of Applied Information Technology \\ Zürich University of Applied Sciences, Winterthur, Switzerland \\ ${ }^{3}$ Orthopaedic and Injury Biomechanics Group \\ ${ }^{4}$ Centre for Hip Health and Mobility \\ ${ }^{5}$ Department of Mechanical Engineering \\ ${ }^{6}$ Department of Orthopedics \\ University of British Columbia, Vancouver, Canada. \\ ${ }^{7}$ Department of Industrial, Mechanical and Computer Engineering \\ University of Iceland, Reykjavik, Iceland.
}

Submitted to Elsevier

R2: 08.04.2016

*Corresponding author

Dr. Benedikt Helgason (bhelgason@ethz.ch)

Institute for Biomechanics

ETH Zürich

HPP-O12, Hönggerbergring 64

CH-8093 Zürich

Tel: +41446332088 


\section{Key words}

Osteoporosis, femur, finite element analysis, mechanical testing, validation

\section{Abstract}

Contributing to slow advance of Finite Element (FE) simulations for hip fracture risk prediction, into clinical practice, could be a lack of consensus in the biomechanics community on how to map properties to the models. Thus, the aim of the present study was first, to systematically quantify the influence of the modulus-density relationship (E- $\rho)$ and the material mapping method (MMM) on the predicted mechanical response of the proximal femur in a side-ways fall (SWF) loading configuration and second, to perform a model-to-model comparison of the predicted mechanical response within the femoral neck for all the specimens tested in the present study, using three different modelling techniques that have yielded good validation outcome in terms of surface strain prediction and whole bone response according to the literature. We found the outcome to be highly dependent on both the E- $\rho$ relationship and the MMM. In addition, we found that the three modelling techniques that have resulted in good validation outcome in the literature yielded different principal strain prediction both on the surface as well as internally in the femoral neck region of the specimens modelled in the present study. We conclude that there exists a need to carry out a more comprehensive validation study for the SWF loading mode to identify which combination of MMMs and E- $\rho$ relationship leads to the best match for whole bone and local mechanical response. The MMMs tested in the present study have been made publicly available at https://simtk.org/home/mitk-gem. 


\section{Introduction}

Since the pioneering work of Lotz et al. $[1,2]$ was published, quantitative computed tomography (QCT) based Finite Element (FE) models of the proximal femur have been validated against in-vitro test results in numerous studies (Table 1). They differ in at least three important aspects: First, the loading mode (single leg stance (SLS) or sideways fall (SWF)); second, the modulus-density (E- $\rho$ ) relationships used to map calibrated CT based mechanical properties to the FE models; and third, the correction of partial volume artifacts implemented into the material mapping method (MMM), which influences the mechanical properties assigned to the bone surface.

In SLS mode, good correlation and good magnitude agreement between in-vitro experimental test results and predicted mechanical response were reported for local strains by [3-8], and whole bone stiffness or displacement by [5, 7], and predicted fracture force by [3]. Yet the moduli resulting from the different E- $\rho$ relationships used by these authors, differ as much as $80 \%$ in the cancellous bone range and as high as $40 \%$ in the cortical range (Fig. 1). The measures undertaken to correct partial volume artifacts in these studies ranged from no correction [5] to covering the surface of the FE models with a layer of shell elements and assigning cortical bone properties to them [3].

Using the same modeling technique as was presented by Schileo et al. [5], Grassi et al. [9], reported relatively good agreement in local strain comparison and whole bone stiffness in a SWF configuration. However, the strain gauges mounted on the superior and anterior parts of the femoral neck showed absolute errors as high as $100 \%$ in some cases, with the FE models systematically overestimating the strains. This raises the question whether the sub-optimal results for the critical strain gauge locations can be attributed to the MMM not capturing the thin cortical shell in the superior femoral neck. With a similar experimental setup, and using the same E- $\rho$ relationship as Grassi et al. [9], Dragomir-Daescu et al. [10] reported good correlation in overall stiffness comparison in SWF loading mode but with the FE models systematically overestimating the 
stiffness for the stiffest specimens. The same trend was reported by Dall'Ara et al. [11] who used voxel-based FE models and a different E- $\rho$ relationship to that of the study of Grassi et al. [9].

The influence of the E- $\rho$ relationship on the simulated mechanical response of the proximal femur has been investigated by [4, 7, 8, 12], while the influence of the MMM was studied by [13] and [14] but only in SLS mode. The combined influence of the MMM and the E- $\rho$ relationship on the predicted mechanical response of the proximal femur in the clinically important SWF loading configuration has never been compared to the same experimental data. Thus, the first aim of the present study was to carry out such a comparison. The second aim was to compare the predicted mechanical response within the femoral neck between three different modelling techniques that have yielded the best validation outcome in the literature in terms of local strain measurements and whole bone response, to evaluate whether these techniques actually produce similar predicted strain distributions in SWF loading configuration.

\section{Materials and methods}

\section{Experimental testing}

The present study used 16 out of 17 fresh frozen specimens tested previously (group Fall:FS from [15]) (table 3). The experimental protocol is only briefly described here for clarity. The specimens were scanned at $41 \mu \mathrm{m}$ isotropic voxel size in an HR-pQCT scanner (XtremeCT, Scanco, Inc., Switzerland) calibrated with a standardized hydroxyapatite phantom (Q1 Scanco phantom with probes of $0,100,200,400$ and $800 \mathrm{mgHA})$. One of the specimens was excluded in present study due to incomplete image data. Prior to testing the shaft of the specimens were potted in an aluminum cylinder using polymethylemethacrylate (PMMA, Bosworth Co, Skokie, IL) (Fig. 2). A single strain rosette was applied to the anterior-superior surface of the neck, a location where fracture often initiates in experimentally simulated side-ways fall [16], using a validated technique [17]. 
The specimens were positioned using a standard fall configuration [18] in a materials testing machine (8874, Instron Inc., Norwood, MA). PMMA pads, approximately $4 \mathrm{~cm}$ in diameter, were formed to the trochanter and head using the platens of the machine. Load was applied to the trochanteric pad with the femoral head supported on the lower platen. The distal end of the specimen was free to rotate in the frontal plane (Fig. 2). A pre-load of $100 \mathrm{~N}$ was applied over 5 seconds and held for 0.5 seconds prior to loading the specimens at $0.5 \mathrm{~mm} / \mathrm{s}$ up to half of their total aBMD predicted failure load [19]. The experimental force-displacement response, which was the force measured by the load cell vs. the displacement of the testing machine crosshead, was corrected for machine compliance and the estimated compliance of the cartilage covering the femoral head, before the slope (whole bone stiffness) of the most linear part of the curve was calculated (Table 3). A simplified FE model (Fig. 2) estimated cartilage deformation between 0.11 $0.20 \mathrm{~mm}$ depending on specimen, which significantly influenced the calculated whole bone stiffness.

\section{Finite Element Analysis}

The high resolution CT data was passed through a morphological filter and resampled to clinicalCT resolution $(0.615 \mathrm{~mm})$ before segmentation was carried out in ITK SNAP (v2.2.0) [20]. The segmented image data was converted to a NURBS based solids in SolidWorks (2008, Dassault Systems, Concord, MA) and subsequently meshed in ANSYS Workbench using 10-node quadratic tetrahedral elements (v.14. ANSYS Inc., Canonsburg, PA, USA).

After segmentation, the outermost layer of voxels within the bone volume typically has CT values that represent sub-cortical density. This is due to the mixture between bone and air/soft tissue within these voxels, an effect often referred to as a partial volume artifact. In effect, this creates a weak voxel layer over the entire surface of the femur. To investigate the influence of various strategies for addressing this, we defined five different MMMs with increasingly aggressive techniques that compensate for the reduced stiffness in the FE models due to the weak voxel layer. These methods 
should conceptually capture the range of methodological differences between MMMs used in previous studies $[3,7,13,14]$. For all the MMMs, voxels strictly inside the volume of the FE model surface were labelled using an in house Matlab script (Matlab Vers. R2012b, MathWorks). Different combinations of custom erosion and dilation procedures were applied to the labelled bone data (Table 4). The purpose of the erosion step was to remove the weak layer from the CT data, but voxels were not removed if the subsequent dilation step resulted in a reduced modulus compared to the originally calculated modulus for the unfiltered CT data. Erosion was either performed once or not performed. The purpose of the dilation steps was to extend the denser bone properties under the weak voxel layer outwards relative to the surface of the bone volume, effectively thickening the cortical shell.

Subsequently the clinical resolution CT image voxel values (in mgHA) were transferred to ash density $\left(\rho_{\text {ash }}\right)$ based on hydroxyapatite (HA) content of the voxels using $\rho_{\text {ash }}=(\mathrm{mgHA} / 1000+0.09) / 1.14 \mathrm{~g} / \mathrm{cm}^{3}[5]$ and then to modulus of elasticity using appropriate densito-metric conversions and one of the 10 modulus-density relationships used in validation studies in the literature where three or more human femoral specimens were used (Table 2). This was followed by a simple tri-linear interpolation scheme introduced by Helgason et al. [14] when mapping the modulus from the $\mathrm{CT}$ grid locations to the FE node locations. For single modulus MMMs (Table 4), the 10 nodal moduli were integrated into a single value for each element using appropriate weighing functions.

Isotropic material behavior was assumed since anisotropy was found to have a minimal impact on the macroscopic mechanical response of the femur in SWF [21, 22]. The Poisson's ratio for bone was set to 0.3. The resulting modulus values from different MMMs are visualized on a sample specimen in Fig. 3. An implementation of these MMMs has been made available in form of a free software tool at (https://simtk.org/home/mitk-gem). 
PMMA pads were meshed using similarly sized elements as were used to mesh the bone. Modulus of elasticity for PMMA was set to 3.1 GPa and Poisson's ratio of 0.3. The interfaces between bone, PMMA, and the loading plate were simulated using a sliding frictionless contact. The head support pad had its bottom (medial) nodes constrained in the loading direction but was allowed to freely translate in a transverse plane. A rigid plate was created above the greater trochanter loading pad, and this plate was displaced by $1 \mathrm{~mm}$.

The distal part of the FE model was modelled with beam elements with hollow cylindrical cross sections closely representing the experimental setup in terms of cross sectional area and flexural rigidity. The distal end of the model was fully translationally constrained, while rotation was only allowed about an axis corresponding to the hinge joint at the distal end. Mesh convergence was investigated using MMM A, with E- $\rho$ relationship II, and an average element edge length of $2.0 \mathrm{~mm}$ was determined to be the optimal compromise between computational cost and accuracy of the force-displacement response at the greater trochanter. The FE equation systems were solved using ANSYS (v.14. ANSYS Inc., Canonsburg, PA, USA).

\section{Comparison between finite element analysis and experimental testing}

The slope of the force-displacement response of the loading plate above the greater trochanter in the FE models was compared to the experimental whole bone stiffness. In addition, principal strains in the FE models were determined by averaging the strain results over all the surface nodes found within the area corresponding to the location and size of the strain gauge (radius of $1.5 \mathrm{~mm}$ ) and compared to the experimental strain results at the maximum force applied on the bones during the experimental testing. A linear regression between experimental and FE-predicted stiffness and local strains was performed, and the slope and the intercept of the regression line determined as well as the coefficient of determination $\left(\mathrm{R}^{2}\right)$, and root mean square error and maximum error. A general linear hypothesis was used to test whether the slope being different from unity and intercept 
different from zero, with $\mathrm{p}<0.05$ (R-Statistics, vers. 3.1.0, ( ) The R Foundation for Statistical Computing).

\section{Comparison between finite element models}

Comparison between 3 different combinations of E- $\rho$ relationships and MMMs was carried out in terms of principal surface strains in the neck, as well as principal strains in the internal structure of the neck for all the 16 bones modelled in the study. The three modelling techniques were as follows, MMM A with E- $\rho$ relationship II, MMM B with E- $\rho$ relationship III, and MMM E with E- $\rho$ relationship IV. These methods were selected to represent the modelling techniques used in the studies of Grassi et al. [9], Wille et al. [7] and Bessho et al [3] respectively. These authors reported correlation coefficients for comparison to experimental data higher than 0.9 with slopes and intercept of regression lines not significantly different from unity and zero respectively for local strain measurements and overall bone response. A linear regression between strain values was determined as well as coefficient of determination $\left(\mathrm{R}^{2}\right)$. A general linear hypothesis was used to test whether the slope being different from unity and intercept different from zero, with $\mathrm{p}<0.05$ (RStatistics, vers. 3.1.0, (O The R Foundation for Statistical Computing)..

\section{Results}

\section{Comparison between finite element analysis and experimental testing}

The comparisons between finite element analysis (FEA) and experimental testing for all the MMMs and E- $\rho$ relationships are listed in Tables 5 and 6. The coefficient of determination between experimentally measured and FEA predicted whole bone stiffness ranged from $\mathrm{R}^{2}=0.63$ to 0.73 depending on E- $\rho$ relationship and MMM. The slope of the regression line and the intercept were not found to be different from unity and zero, respectively, for five E- $\rho$ relationships using MMMs A, B, C and D, and for six E- $\rho$ relationships using MMM E. The variation in RMSE for all the E- $\rho$ 
relationships ranged from $11-41.7 \%, 11.6-46.2 \%, 10.4-43.9 \%, 12.5-49.5 \%$ and $12.7-59.9 \%$ for MMMs A, B, C, D and E respectively. The variation in the stiffness RMSE due to MMM for a given E- $\rho$ relationship was considerably smaller.

The coefficient of determination between experimentally measured and FEA predicted surface strain at the superior/anterior part of the neck ranged from $\mathrm{R}^{2}=0.79$ to 0.91 depending on $\mathrm{E}-\rho$ relationship and MMM. The slope and intercept of the regression were not found to be different from unity and zero respectively for one E- $\rho$ relationship using MMMs A and E, two E- $\rho$ relationships using MMMs B and C, and three E- $\rho$ relationships using MMM D. The variation in RMSE for all the E- $\rho$ relationships ranged from 16.7-143.3\%, 15.4-120.5\%, 14.2-101.7\%, 13.0$61.0 \%$ and $13.0-50.3 \%$ for MMMs A, B, C, D and E respectively. The variation in the surface strain RMSE due to MMM for a given E- $\rho$ relationship was considerably smaller.

The outcome of the regression and corresponding Bland-Altman plots for the three different modelling techniques that have yielded good validation outcome in terms of surface strain prediction and whole bone response according to the literature are illustrated in Fig. 4.

\section{Comparison between finite element models}

The femoral neck strain comparison for the three modelling techniques that we selected from the literature is illustrated in Fig. 5. All the slopes of the regression analysis were found to be significantly different from unity indicating a significant difference in predicted mechanical response in the femoral neck between the methods.

\section{Discussion}

The agreement between experimental and FE-predicted mechanical behavior of the proximal femur in SWF loading, was found to be sensitive to both the modulus-density relationship and MMM used in constructing the FE model. We also found that the three modelling techniques, found in the literature to produce the best agreement with experimental data for SLS loading, yielded 
significantly different principal strain prediction both on the surface as well as internally in the femoral neck region. Comparing FE predicted and experimental mechanical behavior (Tables 5 and 6) we see that the slope of the regression and the intercept with the experimental data were not significantly different from unity and zero, respectively, for both whole bone stiffness and local strain prediction for the following combinations of MMMs and E- $\rho$ relationships: E- $\rho$ relationship I with MMM A, E- $\rho$ relationships I and II with MMM B and C, E- $\rho$ relationships I, III and V with MMM D and E- $\rho$ relationships III with MMM E. These combinations of MMMs and E- $\rho$ relationships represent the modelling techniques that quantitatively match our experimental data. We found slightly lower correlation with whole bone stiffness measurements than previously reported in the literature for similar SWF studies, where our highest values was $R^{2}=0.73$ versus $R^{2}$ $=0.81,0.87$, and 0.74 reported by Keyak et al. [23], Dragomir-Daescu et al. [10] and Dall'Ara et al. [11], respectively. However, these authors did not report whether the slopes of their regressions and intercepts (Table 1) were significantly different from unity and zero respectively thus not allowing for a direct comparison to our study.

For local strain prediction (Table 6), our highest correlation was similar to the SWF study by Grassi et al. $\left(\mathrm{R}^{2}=0.91\right)$, which is still slightly lower correlation than has been reported at best in SLS studies in the literature (see Table 1). It is important to note however, that our experimental data is sparse in terms of number of strain gauges applied to each specimen compared to previous work. However, previous studies have all applied one third or more of the strain gauges used in the experimental setup on the femoral shaft, a region that is to a lesser extent influenced by partial volume artifacts, and thus easier to match in strain prediction than e.g. the femoral neck region. The correlation with the experimental strain data can thus be enhanced by a good match in strain prediction for the shaft. This was alluded to by Grassi et al. [9] that noticed that their errors in surface strain prediction in the superior/anterior part of the neck were higher than in other regions. This is in agreement with our results (MMM A - II, Tables 5 and 6), but despite getting a quantitative match in whole bone stiffness, the predicted strains were higher than the experimental 
strains in the present study. This effect vanishes with increased partial volume artifact corrections (MMMs B and C - II, Tables 5 and 6) at the cost of slightly increased predicted stiffness.

The model-to-model comparisons of femoral neck strains revealed that the three modelling techniques we selected from the literature result in consistently different mechanical response in this critical anatomical region. The predicted whole bone stiffness, which is similar for the methods, appears to be the result of different load distribution between the cortical and cancellous bone compartments. This is of interest since recent high resolution FEA of the proximal femur loaded to fracture in a SWF loading configuration [24] indicates that the failure of the proximal femur starts in the cancellous bone and not the cortical bone.

There are several limitations related to this study. As previously stated, the strain gauges used measured a very limited area. However, the single rosette was strategically placed such that the region most sensitive to this loading configuration is monitored. While additional strain gauges could further characterize the discrepancies between modelling methods, this approach served to address the conceptual question investigated by this study. In addition, we did not implement the MMMs from previous studies directly but instead we implemented a base MMM that we varied in a controlled manner in order to capture the methodological differences of previous work and allow for a meaningful comparison between methods. Thus our data should not be used to identify a single optimal modelling technique for simulating the mechanical response of human femur loaded in a SWF loading configuration but rather to highlight the fundamental differences in available E- $\rho$ relationships and MMMs and their effect on mechanical behavior in FE simulations.

While the comparison between modelling techniques in this study was rigorous, there also remains considerable differences between experimental techniques between all the studies in the literature which directly affects the model validation, namely the boundary conditions. The thicker PMMA caps used by this study could be a major contributor to the greater variance observed in our results and the overall lower correlation in whole bone stiffness. Other studies, using smaller caps and 
metal cups $[9,10]$ have introduced less variance to their validation data, and some of the highest SWF correlations published to date. Thus future studies should seriously consider the boundary conditions of their experiments and specifically how they will be reflected in the FE modelling.

We conclude that further investigation is required including a more comprehensive validation study for the SWF loading configuration using a significant number of strain gauges in the neck and intertrochanteric region or full field Digital Image Correlation techniques. These measurements combined with multiple FE modelling techniques could identify which combination of partial volume artifact correction and E- $\rho$ relationship provide the optimal whole bone and local strain prediction. 


\section{Conflict of Interest}

None.

\section{Acknowledgement}

Funding from the Natural Sciences and Engineering Research Council of Canada (NSERC RGPIN 288148-09) and the Swiss National Science Foundation (project nr. 205321_144435). 


\section{Reference}

[1] Lotz JC, Cheal EJ, Hayes WC. Fracture Prediction for the Proximal Femur Using FiniteElement Models. I. Linear-Analysis. Journal of Biomechanical Engineering-Transactions of the Asme 1991;113: 353-360.

[2] Lotz JC, Gerhart TN, Hayes WC. MECHANICAL-PROPERTIES OF METAPHYSEAL BONE IN THE PROXIMAL FEMUR. J Biomech 1991;24: 317-329.

[3] Bessho M, Ohnishi I, Matsuyama J, Matsumoto T, Imai K, Nakamura K. Prediction of strength and strain of the proximal femur by a CT-based finite element method. J Biomech 2007;40: 1745-53.

[4] Schileo E, Taddei F, Malandrino A, Cristofohni L, Viceconti M. Subject-specific finite element models can accurately predict strain levels in long bones. J Biomech 2007;40: 2982-2989.

[5] Schileo E, Dall'ara E, Taddei F, Malandrino A, Schotkamp T, Baleani M, Viceconti M. An accurate estimation of bone density improves the accuracy of subject-specific finite element models. J Biomech 2008;41: 2483-91.

[6] Trabelsi N, Yosibash Z, Wutte C, Augat P, Eberle S. Patient-specific finite element analysis of the human femur-A double-blinded biomechanical validation. J Biomech 2011;44: 1666-1672.

[7] Wille H, Rank E, Yosibash Z. Prediction of the mechanical response of the femur with uncertain elastic properties. J Biomech 2012;45: 1140-1148.

[8] Eberle S, Gottlinger M, Augat P. An investigation to determine if a single validated densityelasticity relationship can be used for subject specific finite element analyses of human long bones. Med Eng Phys 2013;35: 875-83.

[9] Grassi L, Schileo E, Taddei F, Zani L, Juszczyk M, Cristofolini L, Viceconti M. Accuracy of finite element predictions in sideways load configurations for the proximal human femur. $\mathbf{J}$ Biomech 2012;45: 394-9.

[10] Dragomir-Daescu D, Op Den Buijs J, McEligot S, Dai Y, Entwistle RC, Salas C, Melton LJ, 3rd, Bennet KE, Khosla S, Amin S. Robust QCT/FEA models of proximal femur stiffness and fracture load during a sideways fall on the hip. Ann Biomed Eng 2011;39: 742-55.

[11] Dall'Ara E, Luisier B, Schmidt R, Kainberger F, Zysset P, Pahr D. A nonlinear QCT-based finite element model validation study for the human femur tested in two configurations in vitro. Bone 2013;52: 27-38.

[12] Yosibash Z, Padan R, Joskowicz L, Milgrom C. A CT-based high-order finite element analysis of the human proximal femur compared to in-vitro experiments. Journal of Biomechanical Engineering-Transactions of the Asme 2007;129: 297-309.

[13] Taddei F, Schileo E, Helgason B, Cristofolini L, Viceconti M. The material mapping strategy influences the accuracy of CT-based finite element models of bones: an evaluation against experimental measurements. Med Eng Phys 2007;29: 973-9.

[14] Helgason B, Taddei F, Palsson H, Schileo E, Cristofolini L, Viceconti M, Brynjolfsson S. A modified method for assigning material properties to FE models of bones. Med Eng Phys 2008;30: 444-53.

[15] Gilchrist S, Nishiyama KK, de Bakker P, Guy P, Boyd SK, Oxland T, Cripton PA. Proximal femur elastic behaviour is the same in impact and constant displacement rate fall simulation. $\mathrm{J}$ Biomech 2014;47: 3744-9.

[16] de Bakker PM, Manske SL, Ebacher V, Oxland TR, Cripton PA, Guy P. During sideways falls proximal femur fractures initiate in the superolateral cortex: evidence from high-speed video of simulated fractures. J Biomech 2009;42: 1917-25.

[17] Viceconti M, Toni, A., Giunti, A.,. Strain gauge analysis of hard tissues: factors influencing measurements. In: Experimental Mechanics: Technology Transfer Between High Tech Engineering and Biomechanics (Clinical Aspects of Biomedicine). Amsterdam: Elsevier Science; 1992.

[18] Courtney AC, Wachtel EF, Myers ER, Hayes WC. Effects of loading rate on strength of the proximal femur. Calcif Tissue Int 1994;55: 53-8. 
[19] Boehm HF, Horng A, Notohamiprodjo M, Eckstein F, Burklein D, Panteleon A, Lutz J, Reiser M. Prediction of the fracture load of whole proximal femur specimens by topological analysis of the mineral distribution in DXA-scan images. Bone 2008;43: 826-831.

[20] Yushkevich PA, Piven J, Hazlett HC, Smith RG, Ho S, Gee JC, Gerig G. User-guided 3D active contour segmentation of anatomical structures: Significantly improved efficiency and reliability. Neuroimage 2006;31: 1116-1128.

[21] Luisier B, Dall'Ara E, Pahr DH. Orthotropic HR-pQCT-based FE models improve strength predictions for stance but not for side-way fall loading compared to isotropic QCT-based FE models of human femurs. J Mech Behav Biomed Mater 2014;32: 287-99.

[22] Enns-Bray WS, Owoc JS, Nishiyama KK, Boyd SK. Mapping anisotropy of the proximal femur for enhanced image based finite element analysis. J Biomech 2014;47: 3272-8.

[23] Keyak JH. Improved prediction of proximal femoral fracture load using nonlinear finite element models. Medical Engineering \& Physics 2001;23: 165-173.

[24] Nawathe S, Akhlaghpour H, Bouxsein ML, Keaveny TM. Microstructural failure mechanisms in the human proximal femur for sideways fall loading. J Bone Miner Res 2014;29: 507-15.

[25] Keyak JH, Rossi SA, Jones KA, Skinner HB. Prediction of femoral fracture load using automated finite element modeling. J Biomech 1998;31: 125-133.

[26] Lengsfeld M, Schmitt J, Alter P, Kaminsky J, Leppek R. Comparison of geometry-based and CT voxel-based finite element modelling and experimental validation. Med Eng Phys 1998;20: 51522.

[27] Cody DD, Gross GJ, Hou FJ, Spencer HJ, Goldstein SA, Fyhrie DP. Femoral strength is better predicted by finite element models than QCT and DXA. J Biomech 1999;32: 1013-1020.

[28] Duchemin L, Mitton D, Jolivet E, Bousson V, Laredo JD, Skalli W. An anatomical subjectspecific FE-model for hip fracture load prediction. Computer Methods in Biomechanics and Biomedical Engineering 2008;11: 105-111.

[29] Trabelsi N, Yosibash Z. Patient-Specific Finite-Element Analyses of the Proximal Femur with Orthotropic Material Properties Validated by Experiments. Journal of Biomechanical Engineering-Transactions of the Asme 2011;133.

[30] Koivumaki JE, Thevenot J, Pulkkinen P, Kuhn V, Link TM, Eckstein F, Jamsa T. CT-based finite element models can be used to estimate experimentally measured failure loads in the proximal femur. Bone 2012;50: 824-9.

[31] Hambli R, Allaoui S. A robust 3D finite element simulation of human proximal femur progressive fracture under stance load with experimental validation. Ann Biomed Eng 2013;41: 2515-27.

[32] Nishiyama KK, Gilchrist S, Guy P, Cripton P, Boyd SK. Proximal femur bone strength estimated by a computationally fast finite element analysis in a sideways fall configuration. $\mathrm{J}$ Biomech 2013;46: 1231-6.

[33] Helgason B, Perilli E, Schileo E, Taddei F, Brynjolfsson S, Viceconti M. Mathematical relationships between bone density and mechanical properties: a literature review. Clin Biomech (Bristol, Avon) 2008;23: 135-46.

[34] Duchemin L, Bousson V, Raossanaly C, Bergot C, Laredo JD, Skalli W, Mitton D. Prediction of mechanical properties of cortical bone by quantitative computed tomography. Med Eng Phys 2008;30: 321-8.

[35] Morgan EF, Bayraktar HH, Keaveny TM. Trabecular bone modulus-density relationships depend on anatomic site. J Biomech 2003;36: 897-904.

[36] Keyak JH, Lee IY, Skinner HB. Correlations between orthogonal mechanical properties and density of trabecular bone: use of different densitometric measures. J Biomed Mater Res 1994;28: 1329-36.

[37] Keller TS. Predicting the compressive mechanical behavior of bone. J Biomech 1994;27: 1159-68. 
[38] Les CM, Keyak JH, Stover SM, Taylor KT, Kaneps AJ. Estimation of material properties in the equine metacarpus with use of quantitative computed tomography. J Orthop Res 1994;12: 82233.

[39] Orr TE, Beaupre GS, Carter DR, Schurman DJ. Computer predictions of bone remodeling around porous-coated implants. J Arthroplasty 1990;5: 191-200.

[40] Carter DR, Hayes WC. Compressive Behavior of Bone as a 2-Phase Porous Structure. Journal of Bone and Joint Surgery-American Volume 1977;59: 954-962.

[41] Sran MM, Khan KM, Keiver K, Chew JB, McKay HA, Oxland TR. Accuracy of DXA scanning of the thoracic spine: cadaveric studies comparing BMC, areal BMD and geometric estimates of volumetric BMD against ash weight and CT measures of bone volume. European Spine Journal 2005;14: 971-976.

[42] Besl PJ, McKay ND. A method for registration of 3-D shapes. Ieee Transactions on Pattern Analysis and Machine Intelligence 1992;14: 239-256.

[43] Burgin LV, Edelsten L, Aspden RM. The mechanical and material properties of elderly human articular cartilage subject to impact and slow loading. Med Eng Phys 2014;36: 226-32. 
Table 1 A review of previous proximal femur validation studies in the literature where three or more specimens were used to investigate the mechanical response of the proximal femur. The E- $\rho$ relationships are listed in Table 2. SLS: single leg stance; SWF: sideways fall; EXP: experimental results; FE: simulation results; bFEMs: Finite Element Models based on accurate representation of the bone surface; voxel FEMs: Finite Element Models based on a CT voxel to Finite Element conversion; $F$ : fracture force; $K$ : stiffness; $C$ : compliance; $u$ : displacement; $\varepsilon$ : principal strain; $\sigma$. principal stress; $P$ : principal strain and displacement data pooled together. $(*)$ The percentage RMS error was calculated based on the range of the measured values. (\&) The percentage RMS error was calculated based on the maximum measured value. (+) Calculated by pooling data from the 18 specimens. The percentage RMS error was calculated based on the maximum measured value. (\#): The prediction errors in the study were reported as 1.96SD, average, $+1.96 \mathrm{SD}$ where $\mathrm{SD}=$ standard deviation.

\begin{tabular}{|c|c|c|c|c|c|c|c|c|}
\hline Study & $\begin{array}{l}\text { Loading } \\
\text { mode }\end{array}$ & $\begin{array}{l}\text { Number of } \\
\text { specimens }\end{array}$ & E-p relationship & $\begin{array}{c}\text { Material } \\
\text { Mapping } \\
\text { Method }\end{array}$ & Model Type & $\begin{array}{c}\text { Correlation between experimental } \\
\text { results and FEA }\end{array}$ & Correlation & Prediction error \\
\hline [25] & $\begin{array}{l}\text { SLS } \\
\text { SWF } \\
\text { Pooled }\end{array}$ & $\begin{array}{l}18 \\
17 \\
35\end{array}$ & IV & A & $\begin{array}{l}8 \text { node voxel } \\
\text { FEMs }\end{array}$ & $\begin{array}{c}F_{E X P}=1.66 F_{F E}+0.985 \\
F_{E X P}=1.24 F_{F E}^{1.22} \\
F_{E X P}=1.29 F_{F E}^{1.23}\end{array}$ & $\begin{array}{l}\mathrm{R}=0.867 \\
\mathrm{R}=0.949 \\
\mathrm{R}=0.967\end{array}$ & NA \\
\hline [26] & SLS & 5 & $\begin{array}{l}\mathrm{E}_{\text {cort }}=15000 \mathrm{MPa} \\
\mathrm{E}_{\text {canc }}=1100 \mathrm{MPa}\end{array}$ & - & $\begin{array}{c}8 \text { node voxel } \\
\text { FEMs } \\
10 \text { node } \\
\text { tetrahedral } \\
\text { bFEMs }\end{array}$ & $\begin{array}{c}\sigma_{E X P}=0.8431 \sigma_{F E}-0.7404 \\
\sigma_{E X P}=0.8966 \sigma_{F E}-0.7554\end{array}$ & $\begin{array}{l}\mathrm{R}^{2}=0.8541 \\
\mathrm{R}^{2}=0.8351\end{array}$ & NA \\
\hline [27] & SLS & 25 & IX & A & $\begin{array}{l}8 \text { node voxel } \\
\text { FEMs }\end{array}$ & $F_{F E}=0.8534 F_{E X P}+2.1648$ & $\mathrm{R}^{2}=0.8373$ & NA \\
\hline [23] & SLS & 18 & IV & A & $\begin{array}{l}8 \text { node voxel } \\
\text { FEMs }\end{array}$ & $\begin{array}{c}F_{E X P}=0.77 F_{F E}+1.15 \\
C_{E X P}=2.30 C_{F E}+0.017\end{array}$ & $\begin{array}{l}R=0.962 \\
R=0.902\end{array}$ & $\begin{array}{c}13 \%^{(*)} \\
\text { NA }\end{array}$ \\
\hline [3] & SLS & 11 & IV & $\mathrm{E}$ & $\begin{array}{c}10 \text { node } \\
\text { tetrahedral } \\
\text { bFEMs } \\
\text { covered with } \\
6 \text { node shell } \\
\text { elements }\end{array}$ & $\begin{array}{c}F_{E X P}=0.936 F_{F E}+642 \\
\varepsilon_{E X P}=0.912 \varepsilon_{F E}-16.7\end{array}$ & $\begin{array}{l}\mathrm{R}=0.979 \\
\mathrm{R}=0.963\end{array}$ & $\begin{array}{l}\text { NA } \\
\text { NA }\end{array}$ \\
\hline
\end{tabular}




\begin{tabular}{|c|c|c|c|c|c|c|c|c|}
\hline [4] & SLS & $\begin{array}{l}8 \\
8 \\
8\end{array}$ & $\begin{array}{c}\mathrm{X} \\
\mathrm{VIII} \\
\mathrm{II} \\
\end{array}$ & A & $\begin{array}{l}10 \text { node } \\
\text { tetrahedral } \\
\text { bFEMs }\end{array}$ & $\begin{array}{c}\varepsilon_{F E}=1.43 \varepsilon_{E X P}+38.06 \\
\varepsilon_{F E}=1.89 \varepsilon_{E X P}+40.34 \\
\varepsilon_{F E}=1.01 \varepsilon_{E X P}+6.03\end{array}$ & $\begin{array}{l}\mathrm{R}^{2}=0.554 \\
\mathrm{R}^{2}=0.626 \\
\mathrm{R}^{2}=0.911\end{array}$ & $\begin{array}{l}42.3 \%^{(\&)} \\
53.5 \%^{(\&)} \\
9.8 \%(\&)\end{array}$ \\
\hline [5] & SLS & 8 & II & A & $\begin{array}{l}10 \text { node } \\
\text { tetrahedral } \\
\text { bFEMs }\end{array}$ & $\varepsilon_{F E}=0.97 \varepsilon_{E X P}-2$ & $\mathrm{R}^{2}=0.95$ & $7.2 \%(\&)$ \\
\hline [28] & SLS & 39 & I & A & $\begin{array}{c}8 \text { node } \\
\text { hexahedral } \\
\text { bFEMs }\end{array}$ & $F_{E X P}=1.006 F_{F E}$ & $\mathrm{R}^{2}=0.87$ & NA \\
\hline [29] & SLS & 6 & IV & $\mathrm{B}$ to $\mathrm{C}$ & $\begin{array}{c}\text { p- } \\
\text { formulation } \\
\text { tetrahedral } \\
\text { bFEMs }\end{array}$ & $\begin{aligned} u_{F E} & =0.987 u_{E X P}-89 \\
K_{F E} & =1.367 K_{E X P}+77 \\
\varepsilon_{F E} & =1.036 \varepsilon_{E X P}+30\end{aligned}$ & $\begin{array}{l}\mathrm{R}^{2}=0.871 \\
\mathrm{R}^{2}=0.619 \\
\mathrm{R}^{2}=0.951\end{array}$ & $\begin{array}{l}\text { NA } \\
\text { NA } \\
\text { NA }\end{array}$ \\
\hline [10] & SWF & $2 \times 9$ & II & A & $\begin{array}{l}10 \text { node } \\
\text { tetrahedral } \\
\text { bFEMs }\end{array}$ & $\begin{aligned} K_{E X P} & =0.51 K_{F E}+648.75 \\
K_{E X P} & =0.47 K_{F E}+764.49 \\
F_{E X P} & =1.42 F_{F E}-995.87 \\
F_{E X P} & =1.36 F_{F E}-580.04\end{aligned}$ & $\begin{array}{l}\mathrm{R}^{2}=0.87 \\
\mathrm{R}^{2}=0.87 \\
\mathrm{R}^{2}=0.93 \\
\mathrm{R}^{2}=0.86\end{array}$ & $\begin{array}{l}20.6 \%^{(+)} \\
14.1 \%{ }^{(+)}\end{array}$ \\
\hline [7] & SLS & 2 & $\begin{array}{l}\text { IV } \\
\text { III }\end{array}$ & B to $\mathrm{C}$ & $\begin{array}{c}\mathrm{p}- \\
\text { formulation } \\
\text { tetrahedral } \\
\text { bFEMs } \\
\end{array}$ & $\begin{array}{l}P_{E X P}=0.961 P_{F E}+24.96 \\
P_{E X P}=1.008 P_{F E}+28.15\end{array}$ & $\begin{array}{l}\mathrm{R}^{2}=0.973 \\
\mathrm{R}^{2}=0.978\end{array}$ & NA \\
\hline [30] & SWF & 40 & I & $\mathrm{E}$ & $\begin{array}{c}10 \text { node } \\
\text { tetrahedral } \\
\text { bFEM } \\
\text { covered with } \\
6 \text { node shell } \\
\text { elements } \\
\end{array}$ & $F_{F E}=0.929 F_{E X P}+258$ & $\mathrm{R}=0.931$ & NA \\
\hline [9] & SWF & 3 & II & A & $\begin{array}{l}10 \text { node } \\
\text { tetrahedral } \\
\text { bFEMs }\end{array}$ & $\begin{array}{c}\varepsilon_{F E}=1.06 \varepsilon_{E X P}-6 \\
u_{F E}=0.87 u_{E X P}\end{array}$ & $\begin{array}{l}\mathrm{R}^{2}=0.91 \\
\mathrm{R}^{2}=0.93\end{array}$ & $\begin{array}{l}8.3 \%(\&) \\
11.0 \%(\&)\end{array}$ \\
\hline$[31]$ & SLS & 10 & IV & A & $\begin{array}{l}10 \text { node } \\
\text { tetrahedral } \\
\text { bFEMs } \\
\end{array}$ & $F_{F E}=0.9369 F_{E X P}$ & $\mathrm{R}^{2}=0.9432$ & NA \\
\hline [11] & SLS & $2 \times 36$ & V & A & $\begin{array}{c}8 \text { node voxel } \\
\text { FEMs }\end{array}$ & $K_{E X P}=0.6677 K_{F E}+1938.6$ & $\mathrm{R}^{2}=0.816$ & NA \\
\hline
\end{tabular}




\begin{tabular}{|c|c|c|c|c|c|c|c|c|}
\hline & $\begin{array}{l}\text { SWF } \\
\text { SLS } \\
\text { SWF }\end{array}$ & & & & & $\begin{array}{c}K_{E X P}=0.47 K_{F E}+609.89 \\
F_{E X P}=1.2886 F_{F E}+2472 \\
F_{E X P}=0.9102 F_{F E}+713.26\end{array}$ & $\begin{array}{l}\mathrm{R}^{2}=0.7437 \\
\mathrm{R}^{2}=0.8044 \\
\mathrm{R}^{2}=0.8459\end{array}$ & \\
\hline$[8]$ & $\begin{array}{l}\text { SLS } \\
\text { SLS } \\
\text { SLS }\end{array}$ & 23 & VI & C & $\begin{array}{l}10 \text { node } \\
\text { tetrahedral } \\
\text { bFEMs }\end{array}$ & NA & NA & $\begin{array}{l}-37.6 \%,-10.6 \%,+16.3 \%(\varepsilon)^{(\#)} \\
-56.1 \%,-22.9 \%,+10.4 \%(u)^{(\#)} \\
-10.3 \%, 22.6 \%,+55.5 \%(K)^{(\#)} \\
-46.1 \%,-9.0 \%,+28.2 \%(\varepsilon)^{(\#)} \\
-56.4 \%,-20.9 \%,+14.6 \%(u)^{(\#)} \\
-16.1 \%,+15.8 \%,+47.8 \%(K)^{(\#)} \\
-55.4 \%,+7.9 \%,+71.3 \%(\varepsilon)^{(\#)} \\
-58.4 \%,+1.6 \%,+61.6 \%(u)^{(\#)} \\
-46.7 \%,-9.6 \%,+27.4 \%(K)^{(\#)}\end{array}$ \\
\hline [32] & SWF & 20 & VIII & A & $\begin{array}{c}8 \text { node voxel } \\
\text { FEMs }\end{array}$ & $\begin{aligned} K_{F E A} & =1.07 K_{E X P}-505 \\
F_{F E} & =0.68 F_{E X P}+156\end{aligned}$ & $\begin{array}{l}\mathrm{R}^{2}=0.89 \\
\mathrm{R}^{2}=0.81\end{array}$ & NA \\
\hline
\end{tabular}


Table 2 E- $\rho$ relationships ( $\mathrm{E}$ in $\mathrm{MPa}$ ) used in various Finite Element studies in the literature for simulating the mechanical response of the proximal femur. The relationships are ranked in terms of cancellous bone stiffness at $\rho_{\text {app }}=0.50 \mathrm{~g} / \mathrm{cm}^{3}$ from highest to lowest (I-X). $\rho_{\text {app}}$ : apparent density $\left(\mathrm{g} / \mathrm{cm}^{3}\right) ; \rho_{\text {ash }}$ : ash density $\left(\mathrm{g} / \mathrm{cm}^{3}\right)$; BVF: bone volume fraction (-). For all the MMMs the ash density $\left(\rho_{a s h}\right)$ in each CT voxel was calculated based on hydroxyapatite (HA) content using $\rho_{\text {ash }}=(\operatorname{mgHA} / 1000+0.09) / 1.14 \mathrm{~g} / \mathrm{cm}^{3}$ [5]. To allow for inter-study comparison $\rho_{\text {app }}=1.8 * \mathrm{BVF}$ and $\rho_{\text {app }}=\rho_{\text {ash }} / 0.6$ was assumed in agreement with the studies of [33] and [5] respectively. $(*)$ This E- $\rho$ relationship was first introduced by [28] but according to the study it is based on data from [34].

(**) The strain rate, $\varepsilon$, was set equal to unity in the study of [4].

\begin{tabular}{|c|c|c|c|c|}
\hline & & & \multicolumn{2}{|c|}{ Used in study } \\
\hline $\mathbf{N r}$ & $\begin{array}{c}\text { E- } \rho \text { Relationships } \\
\text { (MPa) }\end{array}$ & $\begin{array}{l}\text { Densito-metric } \\
\text { range }\end{array}$ & $\begin{array}{l}\text { Single leg } \\
\text { stance }\end{array}$ & $\begin{array}{c}\text { Sideways } \\
\text { fall }\end{array}$ \\
\hline I & $E=10^{\prime} 095 \rho_{a s h}[34]^{(*)}$ & Whole range & {$[28]$} & [30] \\
\hline II & $E=66^{\prime} 850 \rho_{\text {app }}^{1.49}[35]$ & Whole range & $\begin{array}{l}{[4]} \\
{[5]} \\
{[8]}\end{array}$ & $\begin{array}{c}{[9]} \\
{[10]}\end{array}$ \\
\hline III & $E=12^{\prime} 000 \rho_{a s h}^{1.45}[7]$ & Whole range & {$[7]$} & - \\
\hline IV & $\begin{array}{l}E=33^{\prime} 900 \rho_{a s h}^{2.20}[36] \\
E=5^{\prime} 307 \rho_{a s h}+469 \text { (interpolation) } \\
E=10^{\prime} 200 \rho_{a s h}^{2.01}[37]\end{array}$ & $\begin{array}{c}\rho_{a s h} \leq 0.27 \\
0.27<\rho_{a s h}<0.60 \\
0.6 \leq \rho_{\text {ash }}\end{array}$ & $\begin{array}{l}25] \\
{[23]} \\
{[3]} \\
{[6]} \\
{[31]}\end{array}$ & [25] \\
\hline $\mathbf{V}$ & $\begin{array}{l}E=6^{\prime} 614 B V F^{1.33} \\
E=6^{\prime} 614\left(B V F^{1.33}+16.614(B V F-0.5)^{2.66}\right) \\
{[11]}\end{array}$ & $\begin{array}{l}B V F \leq 0.5 \\
B V F>0.5\end{array}$ & [11] & [11] \\
\hline VI & $E=10^{\prime} 200 \rho_{a s h}^{2.01}[37]$ & Whole Range & {$[8]$} & - \\
\hline VII & $E=15^{\prime} 100 \rho_{q C T}^{2.25}[38]$ & Whole Range & [8] & - \\
\hline VIII & $E=10^{\prime} 500 \rho_{a s h}^{2.29}[37]$ & Whole Range & {$[4]$} & - \\
\hline IX & $\begin{array}{l}E=3^{\prime} 162 \rho_{a p p}^{2.5} \\
E=2^{\prime} 733 \rho_{a p p}^{3.3}[39]\end{array}$ & $\begin{array}{l}\rho_{\text {app }} \leq 1.2 \\
\rho_{\text {app }}>1.2\end{array}$ & [27] & - \\
\hline $\mathbf{X}$ & $E=3^{\prime} 790(\varepsilon)^{0.06} \rho_{a p p}^{3}[40]^{(* *)}$ & Whole Range & [4] & - \\
\hline
\end{tabular}


Table 3. Details of the 16 femoral specimens used in the present study. L: Left; R: Right; F:

Female; M: Male; NA: Data not available. The specimens were DXA scanned in a clinical scanner (QDR 4500W, Hologic, Bedford, MA) using $4 \mathrm{~kg}$ of rice to simulate soft tissue [41]. Results of the DXA scanning in terms of areal bone mineral density (aBMD), T-scores and WHO osteoporosis classification are indicated.

\begin{tabular}{|l|c|c|c|c|c|c|c|}
\hline Specimen & $\begin{array}{c}\text { Age/Gender } \\
\text { (years/-) }\end{array}$ & $\begin{array}{c}\text { Height/Weight } \\
(\mathbf{m} / \mathbf{k g})\end{array}$ & $\begin{array}{c}\text { Femoral } \\
\text { Neck } \\
\mathbf{a B M D} \\
\left(\mathbf{g} / \mathbf{c m}^{2}\right)\end{array}$ & $\begin{array}{c}\text { Total } \\
\text { aBMD } \\
\left(\mathbf{g} / \mathbf{c m}^{2}\right)\end{array}$ & $\begin{array}{c}\text { T- } \\
\text { score }\end{array}$ & $\begin{array}{c}\text { WHO } \\
\text { classification }\end{array}$ & $\begin{array}{c}\text { Measured } \\
\text { stiffness } \\
\mathbf{( N / m m})\end{array}$ \\
\hline H1167L & $50 / \mathrm{F}$ & $1.68 / 54$ & 0.658 & 0.841 & -0.8 & Normal & 3171 \\
\hline H1168R & $73 / \mathrm{M}$ & $1.70 / 77$ & 0.650 & 0.813 & -1.1 & Osteopenic & 3112 \\
\hline H1268L & $82 / \mathrm{F}$ & NA/NA & 0.536 & 0.698 & -2.0 & Osteopenic & 2268 \\
\hline H1365R & $71 / \mathrm{F}$ & $1.52 / 45$ & 0.504 & 0.638 & -2.5 & Osteoporotic & 2153 \\
\hline H1366R & $73 / \mathrm{F}$ & $\mathrm{NA} / 45$ & 0.740 & 0.839 & -0.8 & Normal & 2378 \\
\hline H1368R & $70 / \mathrm{F}$ & $1.65 / 57$ & 0.500 & 0.606 & -2.8 & Osteoporotic & 1453 \\
\hline H1369L & $69 / \mathrm{F}$ & $1.73 / 68$ & 0.498 & 0.601 & -2.8 & Osteoporotic & 1960 \\
\hline H1372R & $79 / \mathrm{F}$ & $1.68 / 113$ & 0.638 & 0.793 & -1.2 & Osteopenic & 2239 \\
\hline H1373R & $76 / \mathrm{F}$ & $1.52 / 63$ & 0.773 & 0.833 & -0.9 & Normal & 2443 \\
\hline H1374R & $78 / \mathrm{F}$ & $1.45 / 66$ & 0.486 & 0.621 & -2.6 & Osteoporotic & 2843 \\
\hline H1375L & $83 / \mathrm{F}$ & $1.52 / 90$ & 0.633 & 0.782 & -1.3 & Osteopenic & 3304 \\
\hline H1376L & $79 / \mathrm{F}$ & $1.63 / 64$ & 0.552 & 0.683 & -2.1 & Osteopenic & 2780 \\
\hline H1377R & $80 / \mathrm{F}$ & $1.65 / 64$ & 0.503 & 0.627 & -2.6 & Osteoporotic & 1463 \\
\hline H1380R & $71 / \mathrm{F}$ & NA/NA & 0.695 & 0.834 & -0.9 & Normal & 4577 \\
\hline H1381R & $92 / \mathrm{F}$ & $1.63 / 51$ & 0.392 & 0.545 & -3.3 & Osteoporotic & 1763 \\
\hline H1382L & $96 / \mathrm{F}$ & $1.52 / 61$ & 0.441 & 0.546 & -3.2 & Osteoporotic & 1665 \\
\hline
\end{tabular}


Table 4. Details of the 5 heterogeneous MMMs used in the present study. Erosion and dilation steps are carried out on the labelled image data prior to the material mapping.

\begin{tabular}{|c|c|c|c|c|}
\hline & $\begin{array}{c}\text { Erosion } \\
\text { steps }\end{array}$ & $\begin{array}{c}\text { Dilation } \\
\text { steps }\end{array}$ & $\begin{array}{c}\text { Modulus } \\
\text { mapped to: }\end{array}$ & Remarks \\
\hline Method A & 0 & 3 & Elements & $\begin{array}{l}\text { After the dilation steps moduli are mapped to } \\
\text { the nodes of the elements in the FE mesh } \\
\text { using tri-linear interpolation [14] but } \\
\text { subsequently converted to a single modulus } \\
\text { that is applied to the elements. This strategy } \\
\text { gives similar outcome to that of Bonemat V3 } \\
\text { [13] where voxels that are strictly inside the } \\
\text { elements are used to calculate the element } \\
\text { moduli. }\end{array}$ \\
\hline Method B & 1 & 3 & Elements & $\begin{array}{l}\text { Same as A except that the weak voxel layer is } \\
\text { removed prior to the material mapping. }\end{array}$ \\
\hline Method C & 1 & 3 & Nodes & $\begin{array}{l}\text { Moduli mapped to the nodes of the elements } \\
\text { using tri-linear interpolation. }\end{array}$ \\
\hline Method D & 1 & 3 & Nodes & $\begin{array}{l}\text { Same as } \mathrm{C} \text { except that after the tri-linear } \\
\text { interpolation cortical material properties } \\
\text { (using } \rho_{\text {app }}=1.8 \mathrm{~g} / \mathrm{cm}^{3}, \rho_{\text {ash }}=1.08 \mathrm{~g} / \mathrm{cm}^{3} \text { or } \\
\mathrm{BVF}=100 \% \text { depending on the E- } \rho \\
\text { relationship) are assigned to all the surface } \\
\text { nodes of the FE models. This strategy is } \\
\text { based on the observation that the whole bone } \\
\text { surface is covered with a cortical shell. }\end{array}$ \\
\hline Method E & 0 & 3 & Elements & $\begin{array}{l}\text { Same as A except that after the material } \\
\text { mapping the surfaces of the FE models are } \\
\text { covered with 6-node shell elements with } 0.4 \\
\text { mm thickness. The shell elements were } \\
\text { assigned the properties of the underlying } \\
\text { tetrahedral elements but never less than } 10 \\
\text { GPa in accordance with the study of [3]. }\end{array}$ \\
\hline
\end{tabular}


Table 5. Results of linear regression analyses between experimentally derived and FEA derived whole bone stiffness for the 16 femoral specimens used in this study for different E- $\rho$ relationships and MMMs. (+) Slope not significantly different from unity. $\left(^{*}\right)$ Intercept not significantly different from zero.

\begin{tabular}{|c|c|c|c|c|c|c|c|c|c|c|}
\hline & \multicolumn{10}{|c|}{ E- $\rho$ relationship } \\
\hline Method A & I & II & III & IV & V & VI & VII & VIII & IX & $\mathbf{X}$ \\
\hline $\mathbf{R}^{2}$ & 0.65 & 0.72 & 0.71 & 0.71 & 0.73 & 0.72 & 0.73 & 0.72 & 0.72 & 0.72 \\
\hline Slope & $1.30^{(+)}$ & $1.30^{(+)}$ & $1.13^{(+)}$ & $0.95^{(+)}$ & $0.82^{(+)}$ & 0.63 & 0.57 & 0.52 & 0.48 & 0.46 \\
\hline Intercept (N/mm) & $989^{(*)}$ & $246^{(*)}$ & $232^{(*)}$ & $-106^{(*)}$ & $159^{(*)}$ & $-146^{(*)}$ & $-78^{(*)}$ & $-174^{(*)}$ & $-200^{(*)}$ & $-236^{(*)}$ \\
\hline RMSE (N/mm) & 1908 & 1210 & 787 & 539 & 502 & 1133 & 1213 & 1448 & 1558 & 1649 \\
\hline RMSE (\%) & $41.7 \%$ & $26.4 \%$ & $17.2 \%$ & $11.8 \%$ & $11.0 \%$ & $24.8 \%$ & $26.5 \%$ & $31.6 \%$ & $34.0 \%$ & $36.0 \%$ \\
\hline Max error (N/mm) & 3709 & 2594 & 1758 & 1216 & 1212 & 1886 & 1903 & 2204 & 2309 & 2491 \\
\hline Max error (\%) & $81.0 \%$ & $56.7 \%$ & $38.4 \%$ & $26.6 \%$ & $26.5 \%$ & $41.2 \%$ & $41.6 \%$ & $48.2 \%$ & $50.5 \%$ & $54.4 \%$ \\
\hline Method B & I & II & III & IV & V & VI & VII & VIII & IX & $\mathbf{X}$ \\
\hline $\mathbf{R}^{2}$ & 0.63 & 0.69 & 0.69 & 0.69 & 0.71 & 0.70 & 0.71 & 0.70 & 0.70 & 0.71 \\
\hline Slope & $1.33^{(+)}$ & $1.35^{(+)}$ & $1.17^{(+)}$ & $0.98^{(+)}$ & $0.87^{(+)}$ & 0.67 & 0.61 & 0.55 & 0.51 & 0.49 \\
\hline Intercept (N/mm) & $1127^{(*)}$ & $345^{(*)}$ & $318^{(*)}$ & $-51^{(*)}$ & $210^{(*)}$ & $-121^{(*)}$ & $-67^{(*)}$ & $-161^{(*)}$ & $-197^{(*)}$ & $-242^{(*)}$ \\
\hline RMSE (N/mm) & 2113 & 1429 & 962 & 533 & 466 & 1038 & 1118 & 1364 & 1477 & 1571 \\
\hline RMSE (\%) & $46.2 \%$ & $31.2 \%$ & $21.0 \%$ & $11.6 \%$ & $10.2 \%$ & $22.7 \%$ & $24.4 \%$ & $29.8 \%$ & $32.3 \%$ & $34.3 \%$ \\
\hline Max error (N/mm) & 3970 & 2920 & 2151 & 1137 & 1118 & 1817 & 1839 & 2146 & 2244 & 2337 \\
\hline Max error $(\%)$ & $86.7 \%$ & $63.8 \%$ & $47.0 \%$ & $24.8 \%$ & $24.4 \%$ & $39.7 \%$ & $40.2 \%$ & $46.9 \%$ & $49.0 \%$ & $51.1 \%$ \\
\hline Method C & I & II & III & IV & V & VI & VII & VIII & IX & $\mathbf{X}$ \\
\hline $\mathbf{R}^{2}$ & 0.64 & 0.70 & 0.70 & 0.69 & 0.71 & 0.70 & 0.72 & 0.70 & 0.71 & 0.71 \\
\hline Slope & $1.33^{(+)}$ & $1.33^{(+)}$ & $1.15^{(+)}$ & $0.95^{(+)}$ & $0.85^{(+)}$ & 0.64 & 0.56 & 0.51 & 0.48 & 0.46 \\
\hline Intercept (N/mm) & $1016^{(*)}$ & $247^{(*)}$ & $237^{(*)}$ & $-97^{(*)}$ & $199^{(*)}$ & $-120^{(*)}$ & $-91^{(*)}$ & $-142^{(*)}$ & $-158^{(*)}$ & $-195^{(*)}$ \\
\hline RMSE (N/mm) & 2011 & 1283 & 852 & 548 & 477 & 1110 & 1256 & 1423 & 1515 & 1603 \\
\hline RMSE (\%) & $43.9 \%$ & $28.0 \%$ & $18.6 \%$ & $12.0 \%$ & $10.4 \%$ & $24.3 \%$ & $27.4 \%$ & $31.1 \%$ & $33.1 \%$ & $35.0 \%$ \\
\hline Max error (N/mm) & 3864 & 2712 & 1926 & 1232 & 1170 & 1890 & 1973 & 2199 & 2279 & 2450 \\
\hline Max error (\%) & $84.4 \%$ & $59.3 \%$ & $42.1 \%$ & $26.9 \%$ & $25.6 \%$ & $41.3 \%$ & $43.1 \%$ & $48.0 \%$ & $49.8 \%$ & $53.5 \%$ \\
\hline Method D & I & II & III & IV & V & VI & VII & VIII & IX & $\mathbf{X}$ \\
\hline $\mathbf{R}^{2}$ & 0.63 & 0.68 & 0.68 & 0.67 & 0.70 & 0.68 & 0.67 & 0.67 & 0.67 & 0.67 \\
\hline Slope & $1.35^{(+)}$ & $1.37^{(+)}$ & $1.18^{(+)}$ & $1.01^{(+)}$ & $0.98^{(+)}$ & 0.68 & 0.62 & 0.57 & 0.57 & 0.56 \\
\hline Intercept (N/mm) & $1240^{(*)}$ & $588^{(*)}$ & $511^{(*)}$ & $118^{(*)}$ & $658^{(*)}$ & $120^{(*)}$ & $380^{(*)}$ & $104^{(*)}$ & $159^{(*)}$ & $171^{(*)}$ \\
\hline RMSE (N/mm) & 2265 & 1692 & 1168 & 574 & 788 & 801 & 718 & 1072 & 1010 & 1037 \\
\hline RMSE (\%) & $49.5 \%$ & $37.0 \%$ & $25.5 \%$ & $12.5 \%$ & $17.2 \%$ & $17.5 \%$ & $15.7 \%$ & $23.4 \%$ & $22.1 \%$ & $22.7 \%$ \\
\hline Max error (N/mm) & 4302 & 3465 & 2422 & 1311 & 1636 & 1568 & 1386 & 1848 & 1756 & 1751 \\
\hline Max error (\%) & $94.0 \%$ & $75.7 \%$ & $52.9 \%$ & $28.7 \%$ & $35.7 \%$ & $34.3 \%$ & $30.3 \%$ & $40.4 \%$ & $38.4 \%$ & $38.3 \%$ \\
\hline Method E & I & II & III & IV & V & VI & VII & VIII & IX & $\mathbf{X}$ \\
\hline $\mathbf{R}^{2}$ & 0.63 & 0.70 & 0.70 & 0.69 & 0.73 & 0.70 & 0.71 & 0.70 & 0.71 & 0.73 \\
\hline Slope & $1.45^{(+)}$ & $1.45^{(+)}$ & $1.28^{(+)}$ & $1.12^{(+)}$ & $1.00^{(+)}$ & $0.79^{(+)}$ & 0.69 & 0.67 & 0.63 & 0.60 \\
\hline Intercept (N & $1457^{(*)}$ & $675^{(*)}$ & $640^{(*)}$ & $224^{(*)}$ & $556^{(*)}$ & $136^{(*)}$ & $353^{(*)}$ & $78^{(*)}$ & $51^{(*)}$ & $30^{(*)}$ \\
\hline RMSE (N/mm) & 2741 & 1969 & 1504 & 790 & 745 & 579 & 601 & 865 & 967 & 1059 \\
\hline RMSE (\%) & $59.9 \%$ & $43.0 \%$ & $32.9 \%$ & $17.3 \%$ & $16.3 \%$ & $12.7 \%$ & $13.1 \%$ & $18.9 \%$ & $21.1 \%$ & $23.1 \%$ \\
\hline Max error (N/mm) & 5158 & 4018 & 3109 & 1842 & 1522 & 1260 & 1220 & 1612 & 1699 & 1745 \\
\hline Max error (\%) & $112.7 \%$ & $87.8 \%$ & $67.9 \%$ & $40.2 \%$ & $33.3 \%$ & $27.5 \%$ & $26.7 \%$ & $35.2 \%$ & $37.1 \%$ & $38.1 \%$ \\
\hline
\end{tabular}


Table 6. Results of linear regression analyses between experimentally derived and FEA derived principal surface strains in the superior/anterior part of the femoral neck for the 16 specimens used in this study for different E- $\rho$ relationships and MMMs. (+) Slope not significantly different from unity. (*) Intercept not significantly different from zero.

\begin{tabular}{|c|c|c|c|c|c|c|c|c|c|c|}
\hline & \multicolumn{10}{|c|}{ E- $\rho$ relationship } \\
\hline Method A & I & II & III & IV & V & VI & VII & VIII & IX & $\mathbf{X}$ \\
\hline $\mathbf{R}^{2}$ & 0.89 & 0.90 & 0.90 & 0.89 & 0.88 & 0.89 & 0.85 & 0.87 & 0.85 & 0.81 \\
\hline Slope & $1.10^{(+)}$ & 1.21 & 1.43 & 2.08 & 2.22 & 2.72 & 2.25 & 3.32 & 3.52 & 3.36 \\
\hline Intercept $(\mu \varepsilon)$ & $120^{(*)}$ & $43^{(*)}$ & $62^{(*)}$ & $48^{(*)}$ & $-52^{(*)}$ & $-12^{(*)}$ & $-117^{(*)}$ & $-69^{(*)}$ & $-170^{(*)}$ & $-169^{(*)}$ \\
\hline RMSE $(\mu \varepsilon)$ & 573 & 685 & 1002 & 2114 & 2435 & 3299 & 2624 & 4443 & 4924 & 4809 \\
\hline RMSE (\%) & $16.7 \%$ & $19.9 \%$ & $29.2 \%$ & $61.5 \%$ & $70.9 \%$ & $96.0 \%$ & $76.4 \%$ & $129.4 \%$ & $143.3 \%$ & $140.0 \%$ \\
\hline Max error $(\mu \varepsilon)$ & 1386 & 1984 & 2656 & 4997 & 5613 & 7249 & 7126 & 9677 & 10743 & 12189 \\
\hline Max error (\%) & $40.4 \%$ & $57.8 \%$ & $77.3 \%$ & $145.5 \%$ & $163.4 \%$ & $211.0 \%$ & $207.5 \%$ & $281.7 \%$ & $312.8 \%$ & $354.9 \%$ \\
\hline Method B & I & II & III & IV & V & VI & VII & VIII & IX & $\mathbf{X}$ \\
\hline $\mathbf{R}^{2}$ & 0.89 & 0.90 & 0.90 & 0.89 & 0.88 & 0.88 & 0.83 & 0.86 & 0.84 & 0.79 \\
\hline Slope & $1.05^{(+)}$ & $1.11^{(+)}$ & 1.33 & 1.95 & 2.02 & 2.45 & 1.98 & 2.92 & 3.03 & 2.82 \\
\hline Intercept $(\mu \varepsilon)$ & $102^{(*)}$ & $18^{(*)}$ & $38^{(*)}$ & $25^{(*)}$ & $-96^{(*)}$ & $-55^{(*)}$ & $-145^{(*)}$ & $-126^{(*)}$ & $-243^{(*)}$ & $-202^{(*)}$ \\
\hline RMSE $(\mu \varepsilon)$ & 529 & 582 & 846 & 1906 & 2124 & 2847 & 2208 & 3790 & 4140 & 3901 \\
\hline RMSE (\%) & $15.4 \%$ & $16.9 \%$ & $24.6 \%$ & $55.5 \%$ & $61.8 \%$ & $82.9 \%$ & $64.3 \%$ & $110.3 \%$ & $120.5 \%$ & $113.6 \%$ \\
\hline Max error (me) & 1298 & 1574 & 2304 & 4778 & 5275 & 6578 & 6894 & 8671 & 9340 & 11019 \\
\hline Max e & $37.8 \%$ & $45.8 \%$ & $67.1 \%$ & $139.1 \%$ & $153.6 \%$ & $191.5 \%$ & $200.7 \%$ & $252.4 \%$ & $271.9 \%$ & $320.8 \%$ \\
\hline Method C & I & II & III & IV & V & VI & VII & VIII & IX & $\mathbf{X}$ \\
\hline $\mathbf{R}^{2}$ & 0.90 & 0.91 & 0.91 & 0.90 & 0.89 & 0.89 & 0.86 & 0.88 & 0.86 & 0.82 \\
\hline Slope & $1.01^{(+)}$ & $1.06^{(+)}$ & 1.25 & 1.85 & 1.90 & 2.27 & 1.89 & 2.70 & 2.78 & 2.59 \\
\hline Intercept (me) & $109^{(*)}$ & $54^{(*)}$ & $72^{(*)}$ & $57^{(*)}$ & $-13^{(*)}$ & $60^{(*)}$ & $34^{(*)}$ & $42^{(*)}$ & $-25^{(*)}$ & $38^{(*)}$ \\
\hline RMSE (me) & 488 & 501 & 711 & 1702 & 1835 & 2445 & 1876 & 3247 & 3495 & 3246 \\
\hline RMSE (\%) & $14.2 \%$ & $14.6 \%$ & $20.7 \%$ & $49.6 \%$ & $53.4 \%$ & $71.2 \%$ & $54.6 \%$ & $94.5 \%$ & $101.7 \%$ & $94.5 \%$ \\
\hline Max error (me) & 1224 & 1126 & 1723 & 4334 & 4243 & 6261 & 5223 & 8134 & 8662 & 8239 \\
\hline Max error $(\%)$ & $35.6 \%$ & $32.8 \%$ & $50.2 \%$ & $126.2 \%$ & $123.5 \%$ & $182.3 \%$ & $152.1 \%$ & $236.8 \%$ & $252.2 \%$ & $239.9 \%$ \\
\hline Met & I & II & III & IV & $\mathbf{V}$ & VI & VII & VIII & IX & $\mathbf{X}$ \\
\hline $\mathbf{R}^{2}$ & 0.90 & 0.91 & 0.91 & 0.90 & 0.90 & 0.90 & 0.89 & 0.90 & 0.88 & 0.86 \\
\hline Slope & $0.91^{(+)}$ & 0.89 & $1.06^{(+)}$ & 1.45 & $1.04^{(+)}$ & 1.77 & 1.36 & 1.96 & 1.63 & 1.56 \\
\hline Intercept (me) & $73^{(*)}$ & $-27^{(*)}$ & $-20^{(*)}$ & $-62^{(*)}$ & $-113^{(*)}$ & $-216^{(*)}$ & $-270^{(*)}$ & $-338^{(*)}$ & -416 & $-349^{(*)}$ \\
\hline RMSE (me) & 480 & 446 & 502 & 1073 & 533 & 1678 & 1065 & 2095 & 1620 & 1502 \\
\hline RMSE (\%) & $14.0 \%$ & $13.0 \%$ & $14.6 \%$ & $31.2 \%$ & $15.5 \%$ & $48.9 \%$ & $31.0 \%$ & $61.0 \%$ & $47.2 \%$ & $43.7 \%$ \\
\hline Max error (me) & 1404 & 1174 & 1505 & 3011 & 1284 & 4599 & 3312 & 5580 & 3908 & 3839 \\
\hline Max error (\%) & $40.9 \%$ & $34.2 \%$ & $43.8 \%$ & $87.7 \%$ & $37.4 \%$ & $133.9 \%$ & $96.4 \%$ & $162.5 \%$ & $113.8 \%$ & $111.8 \%$ \\
\hline Method E & I & II & III & IV & V & VI & VII & VIII & IX & $\mathbf{X}$ \\
\hline $\mathbf{R}^{2}$ & 0.90 & 0.90 & 0.91 & 0.91 & 0.91 & 0.90 & 0.89 & 0.89 & 0.88 & 0.86 \\
\hline Slope & 0.76 & 0.82 & $0.92^{(+)}$ & 1.17 & 1.16 & 1.42 & 1.29 & 1.58 & 1.62 & 1.61 \\
\hline Intercept & $45^{(*)}$ & $-38^{(*)}$ & $-40^{(*)}$ & $-93^{(*)}$ & $-148^{(*)}$ & $-259^{(*)}$ & -354 & -396 & -512 & -568 \\
\hline RMSE (me) & 583 & 487 & 445 & 645 & 665 & 1114 & 1000 & 1497 & 1664 & 1726 \\
\hline RMSE (\%) & $17.0 \%$ & $14.2 \%$ & $13.0 \%$ & $18.8 \%$ & $19.4 \%$ & $32.4 \%$ & $29.1 \%$ & $43.6 \%$ & $48.4 \%$ & $50.3 \%$ \\
\hline Max error (me) & 1756 & 1461 & 1292 & 2060 & 2078 & 3376 & 3405 & 4420 & 4938 & 5316 \\
\hline Max error $(\%)$ & $51.1 \%$ & $42.5 \%$ & $37.6 \%$ & $60.0 \%$ & $60.5 \%$ & $98.3 \%$ & $99.1 \%$ & $128.7 \%$ & $143.8 \%$ & $154.8 \%$ \\
\hline
\end{tabular}


Fig. 1

Fig. 1. Modulus of elasticity (E) as a function of apparent density $\left(\rho_{\text {app }}\right)$ used in different Finite Element studies in the literature. The roman numerals in the legend refer to the definitions in Table 2.

Fig. 2, above

Fig. 2, below

Fig. 2. Experimental setup (above); corresponding FE model (below-left). An Optotrak Certus motion capture system (Northern Digital Inc, Waterloo, ON, Canada, accuracy $<0.1 \mathrm{~mm}$ ) equipped with a digitizer probe was used to record the locations of landmarks on the femur with respect to the experimental setup to allow for accurate representation of boundary conditions in the FEA. The femur FE models were transferred to the experimental coordinate system through a rigid registration using an iterative closest point algorithm [42]. The FE model used for estimating cartilage compliance is shown below-right. In this model, the femoral head was assumed to be of spherical shape and the diameter of the sphere was varied based on the actual bone geometry of the specimens used in the study. The sphere was assumed to be covered with a cartilage layer of 1.47 mm thickness which was the average cartilage thickness found for cartilage samples harvested from the femoral head around the fovea capitis in the study of [43]. The femoral head in the cartilage FE model was assumed to be embedded $7 \mathrm{~mm}$ into a rigid support. A frictionless sliding $(\mu=0)$ was modelled between the cartilage layer and the rigid support bed. The mechanical properties of cartilage were based on the results from [43] that reported an average stiffness value of $E=1.98$ $\mathrm{MPa}$ at $0.1 \mathrm{MPa}$ pressure for slow loading for cartilage specimens harvested around the fovea capitis. An incompressible, Neo-Hookean hyperelastic material behaviour was assumed to apply and the $\mathrm{C}_{1}$ material constant adjusted until the stiffness value of $1.98 \mathrm{MPa}$ was found at $0.1 \mathrm{MPa}$ pressure. The resulting value for $\mathrm{C}_{1}$ was $0.33 \mathrm{MPa}$. The model was loaded by vertically displacing all the nodes on the cartilage layer assumed to be in contact with the idealised spherically shaped 
femoral head and a corresponding force-displacement relationship, representing the cartilage compliance, recorded.

\begin{tabular}{|c|c|}
\hline Figure 3A & Figure 3B \\
\hline Method A & Method B \\
\hline Figure 3C & Figure 3D \\
\hline Method C & Method D \\
\hline Figure 3E-1 & Figure 3E-2 \\
\hline Method E (solid elements) & Method E (shell elements) \\
\hline \multicolumn{2}{|c|}{ Figure 3-colorbar } \\
\hline
\end{tabular}

Fig. 3. Modulus of elasticity distribution for a sample specimen using different MMMs and E- $\rho$ relationship II. The units of the color code are MPa.

Figure 4

Fig. 4. The outcome of the regression analysis and corresponding Bland-Altman plots for three different modelling techniques that have yielded the best validation outcome for local strain measurements and overall bone response in a SLS loading mode in the literature. The strain values used for this comparison were the principal strain values at corner nodes of the tetrahedral elements of the FE meshes as predicted at the maximum load used in the experimental testing.

\begin{tabular}{|l|l|}
\hline Figure 5-1 & Figure 5-2 \\
\hline Figure 5-3 & Figure 5-4 \\
\hline Figure 5-5 & Figure 5-6 \\
\hline
\end{tabular}

Fig. 5. Comparison of FEA derived principal internal strains (left) and surface strains (right) in the femoral neck volume of interest (VOI) for all the bones used in the present study for MMM A and E- $\rho$ relationship II vs. MMM B and E- $\rho$ relationship III top; MMM B and E- $\rho$ relationship III vs. MMM E and E- $\rho$ relationship IV middle; and MMM A and E- $\rho$ relationship II vs. MMM E and E- $\rho$ relationship IV bottom. 


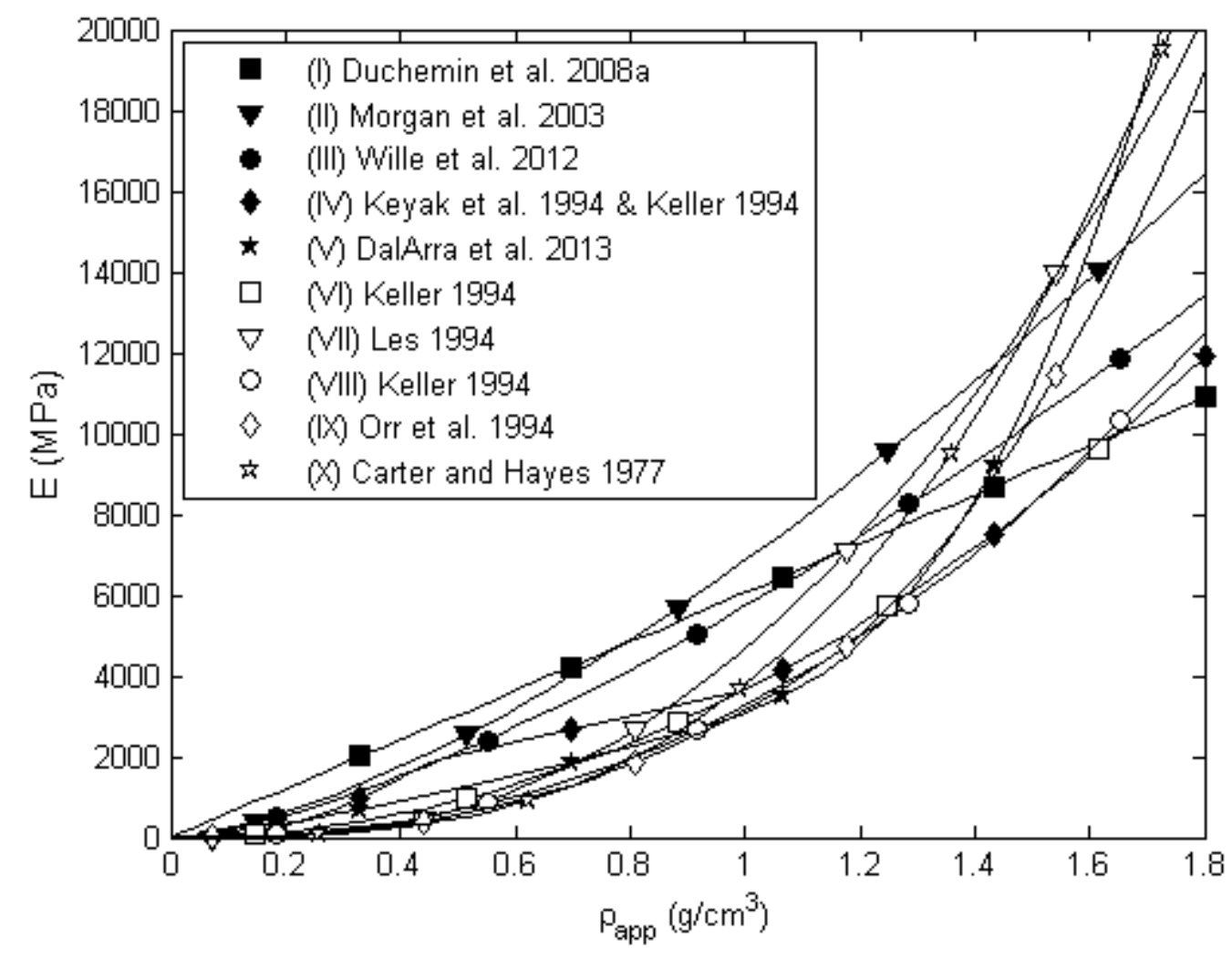




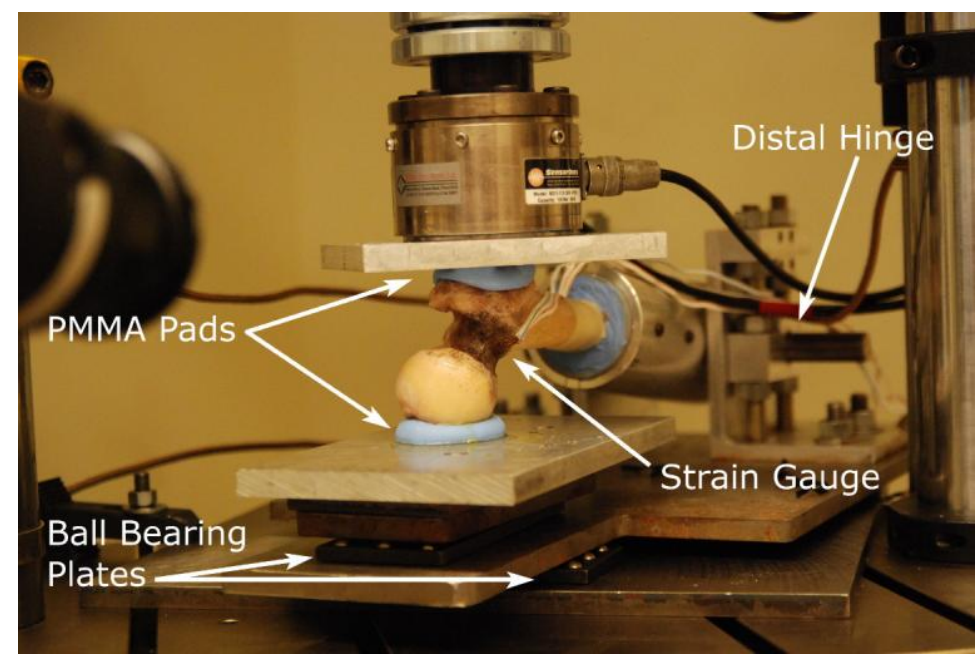




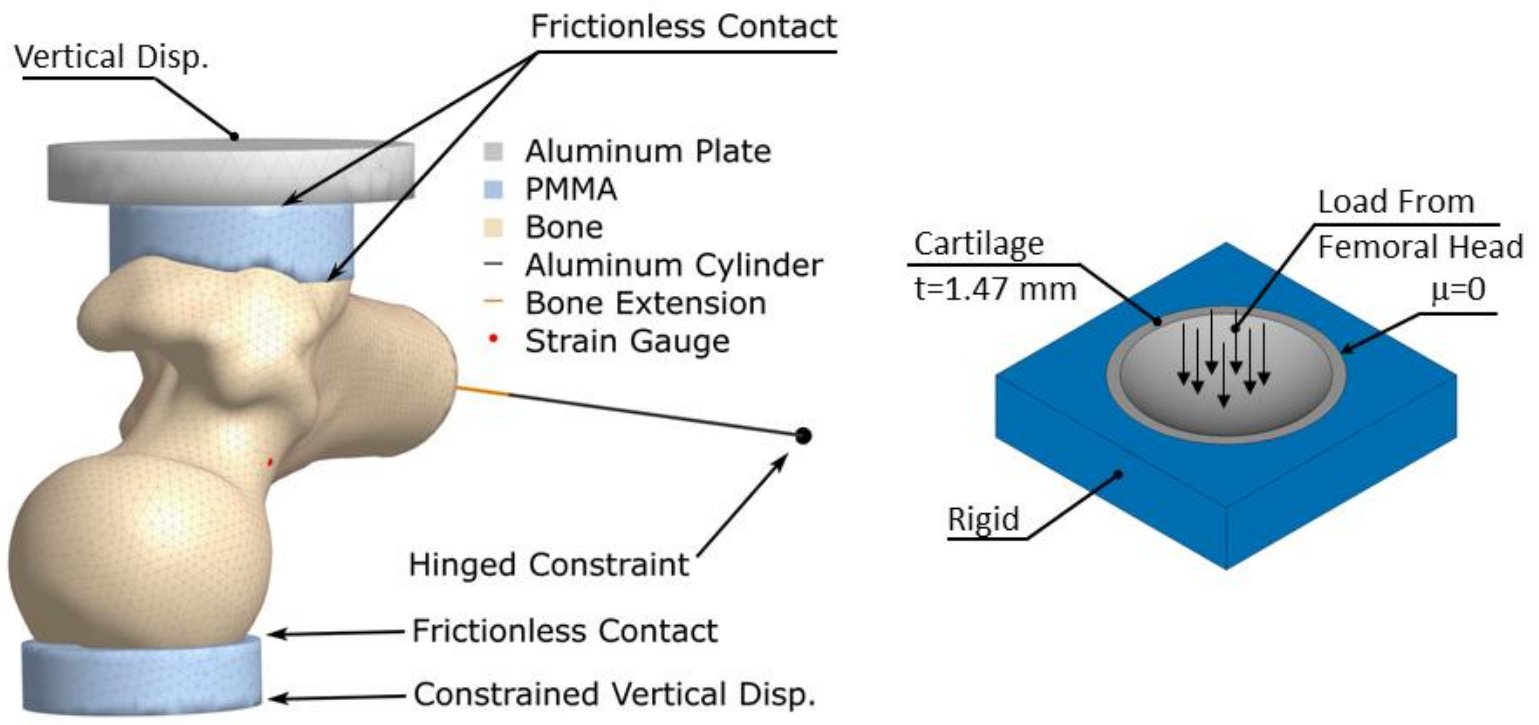




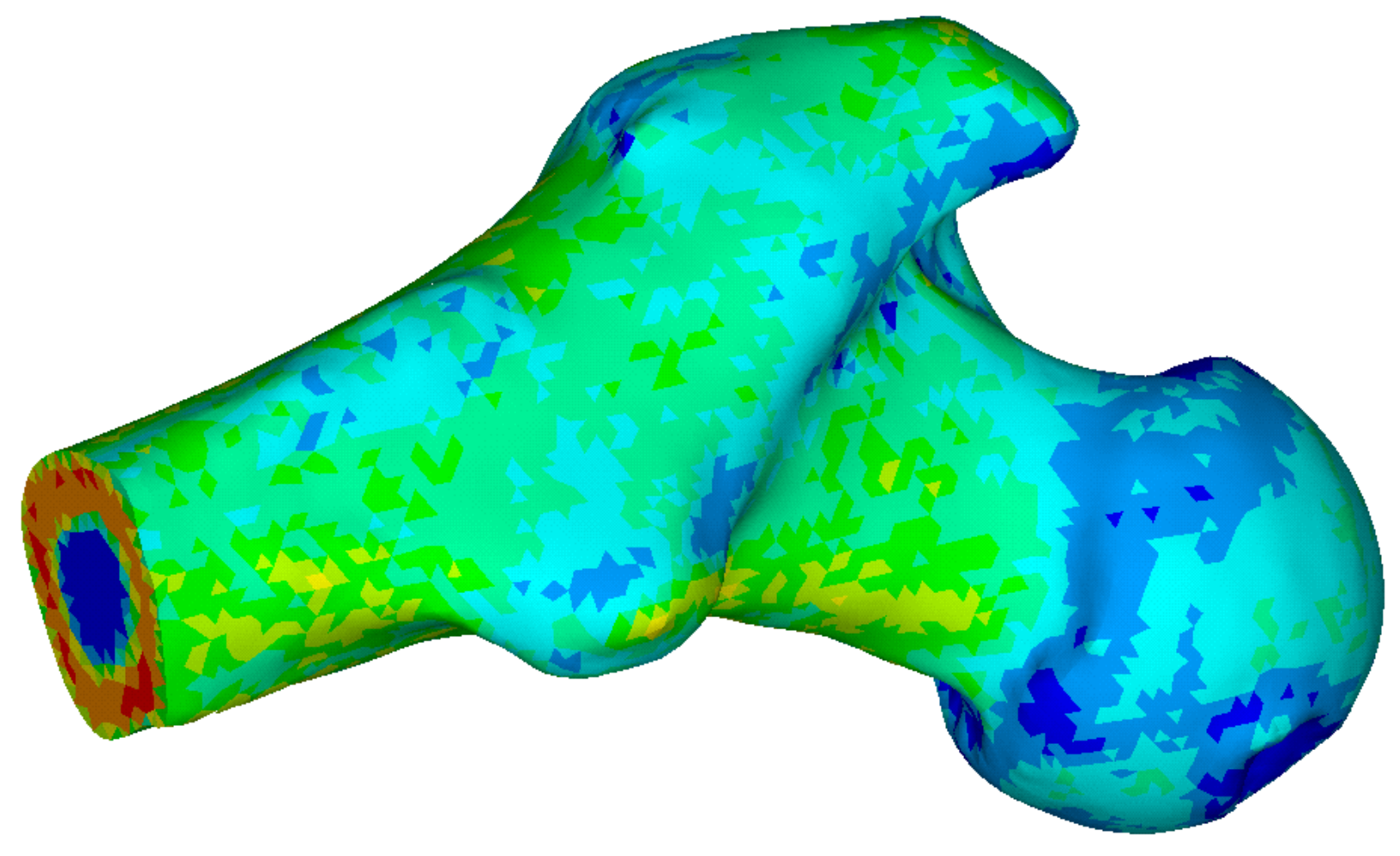




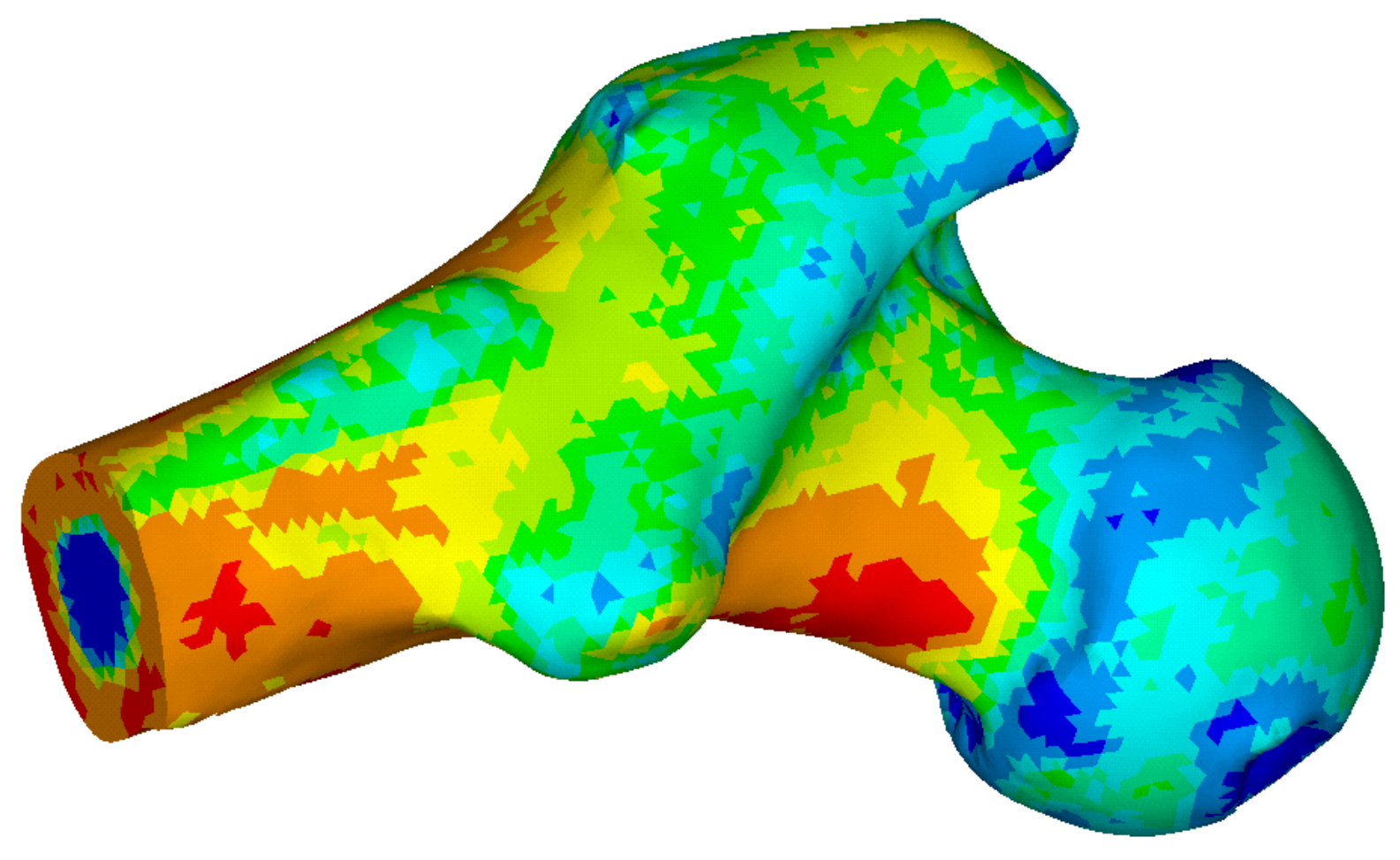




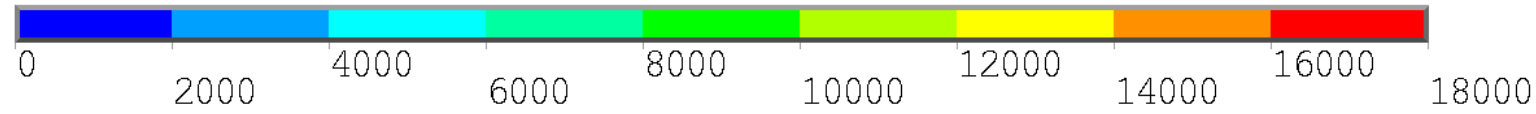




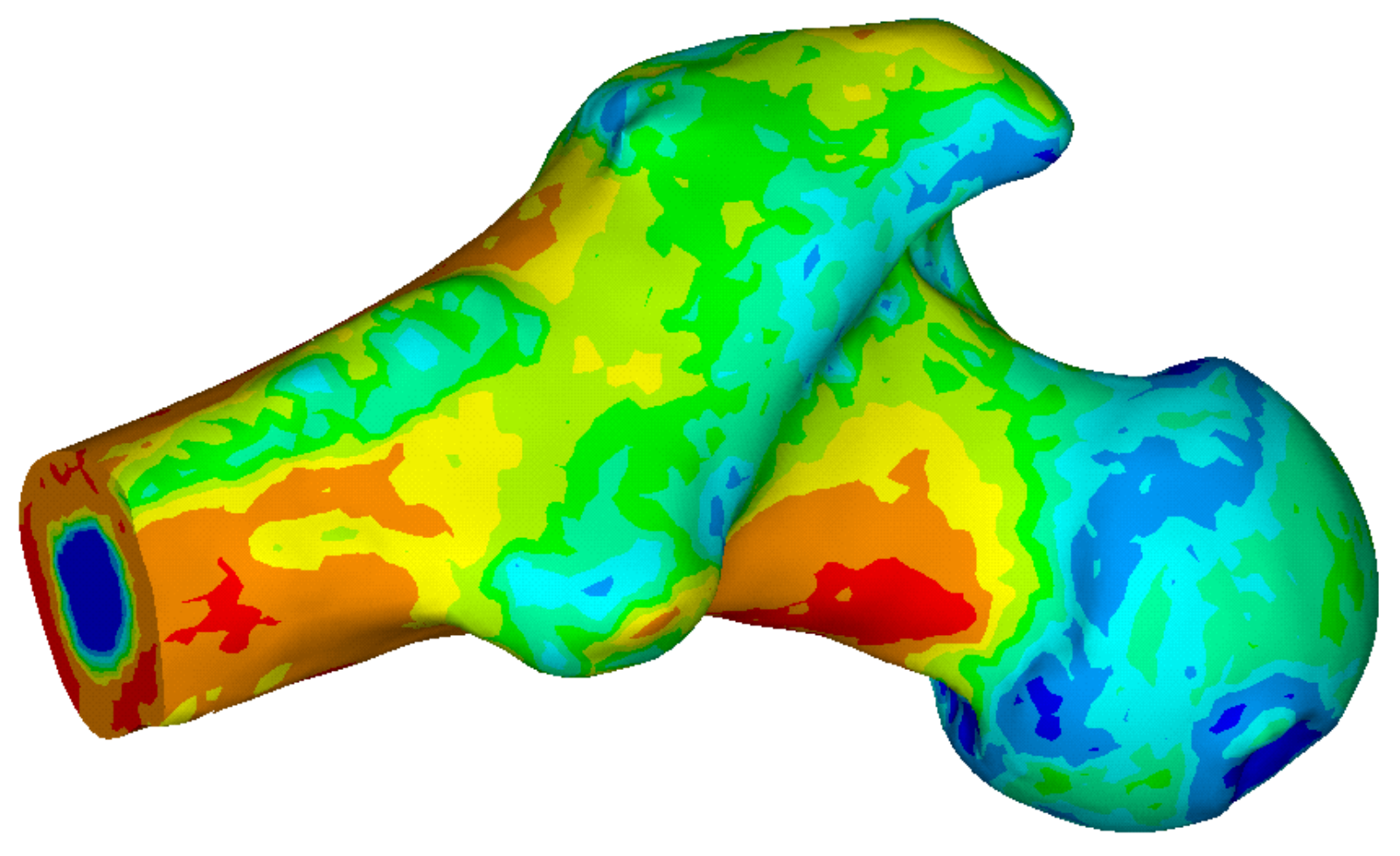





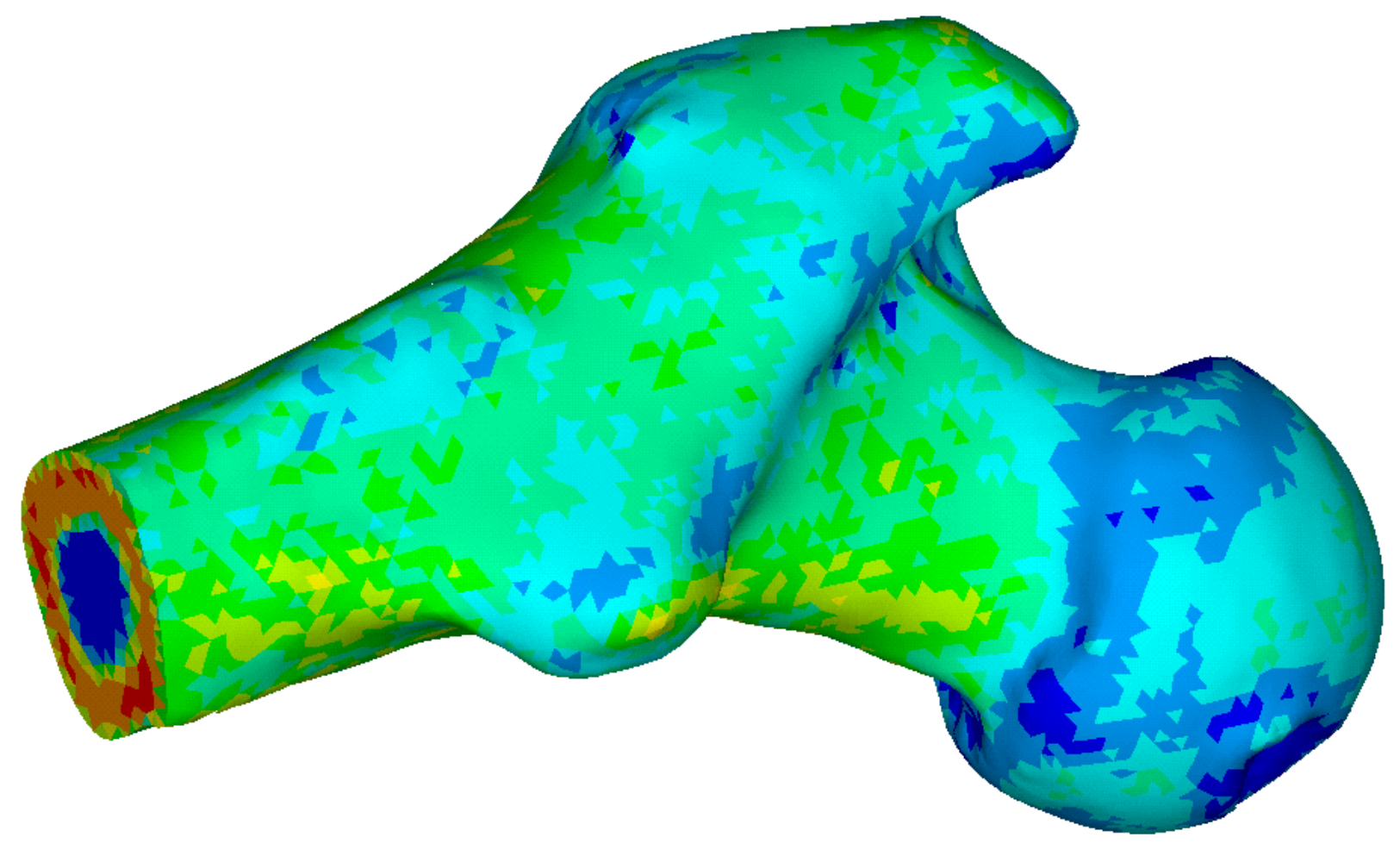




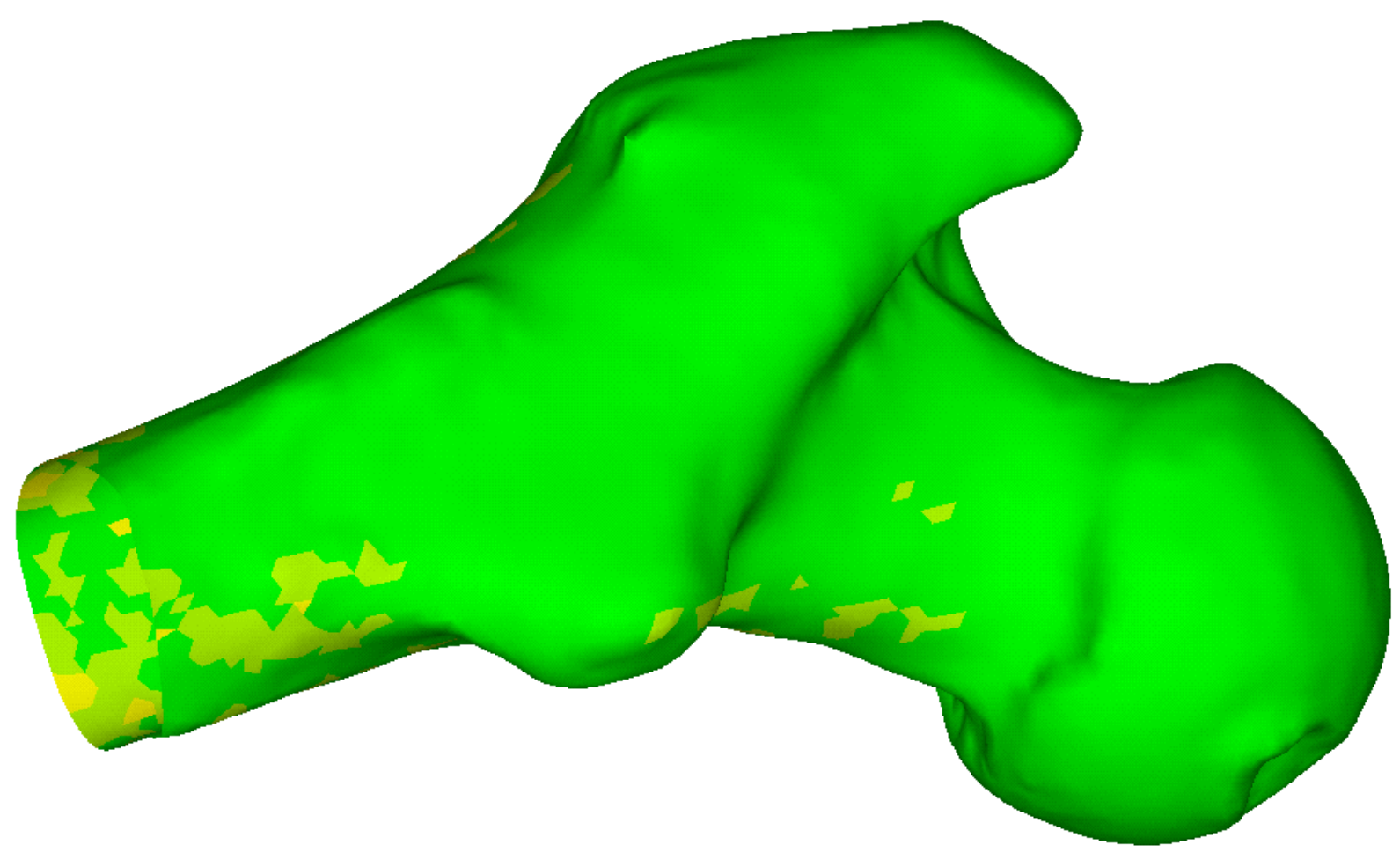



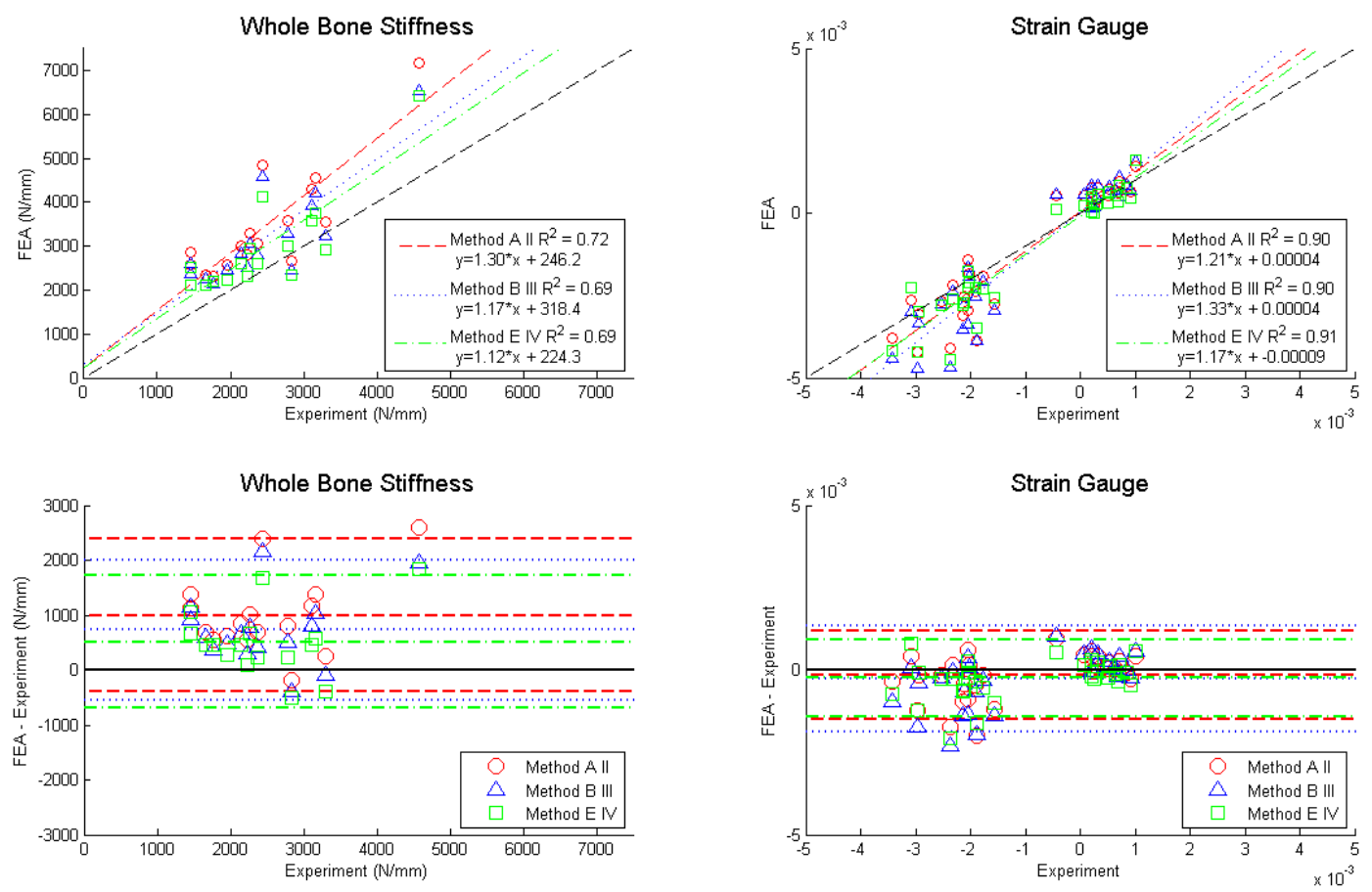


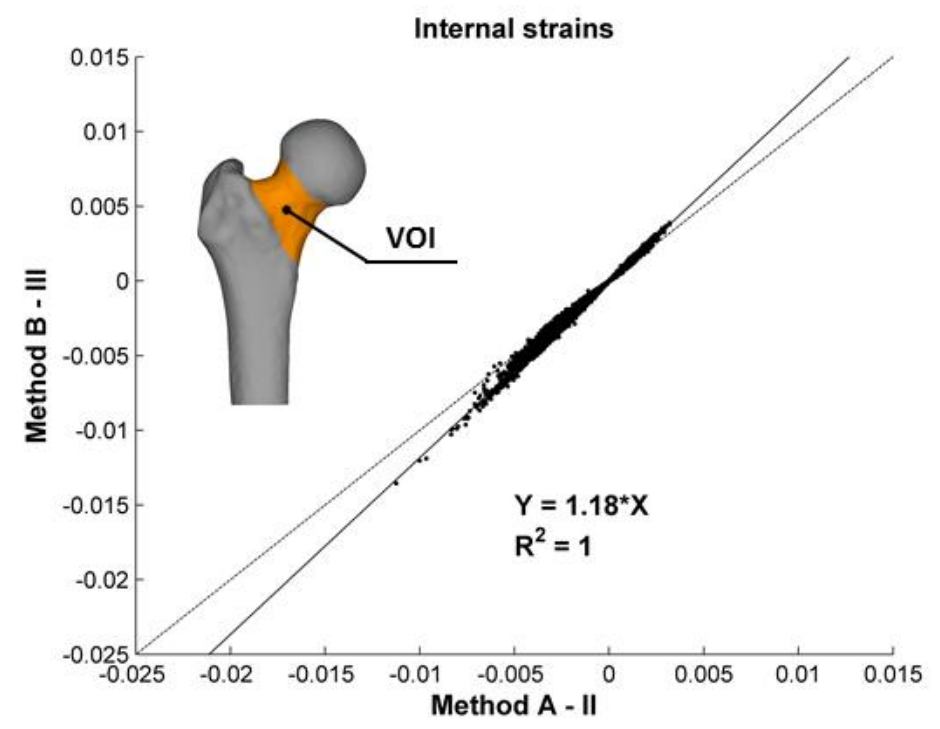




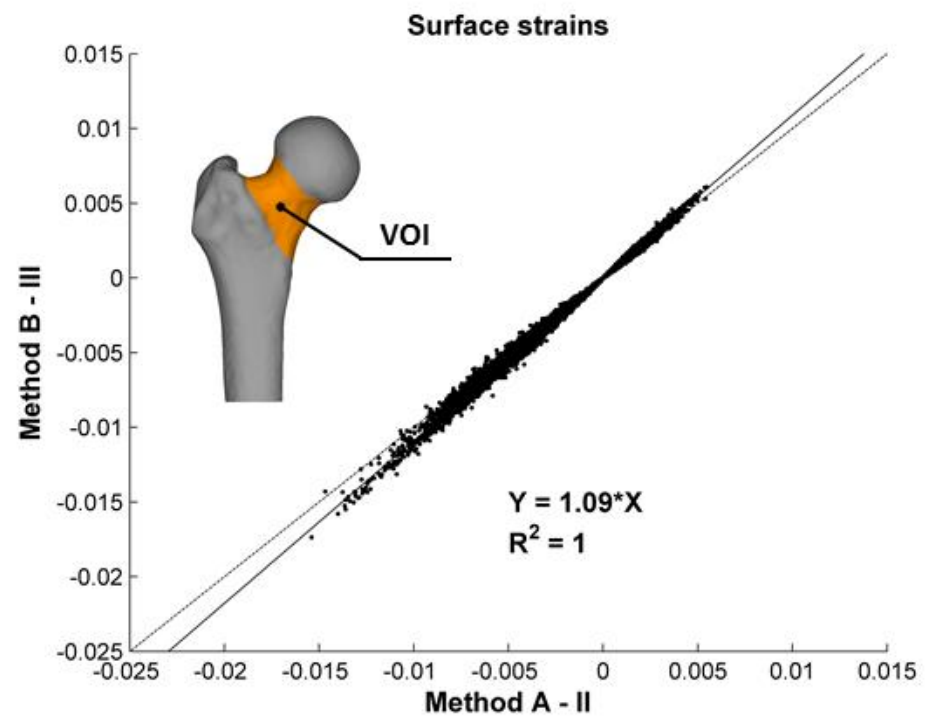




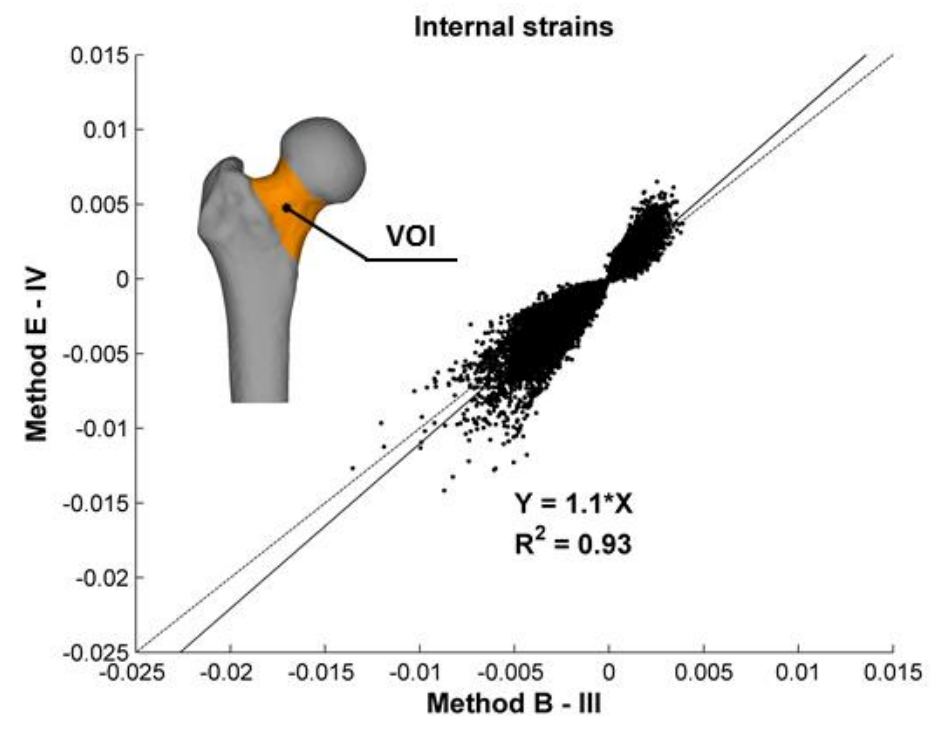




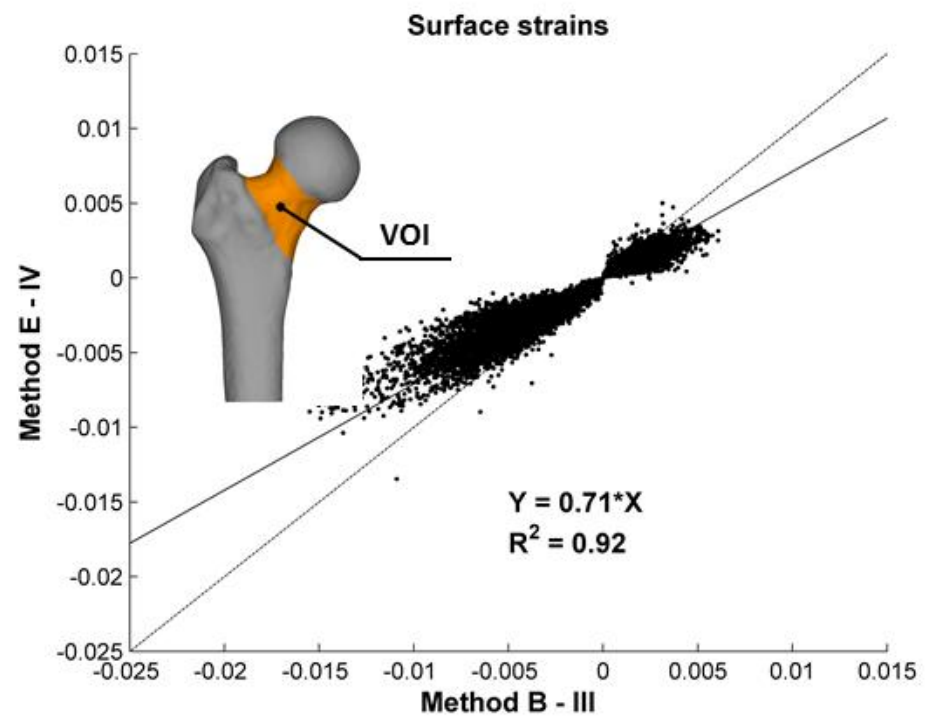




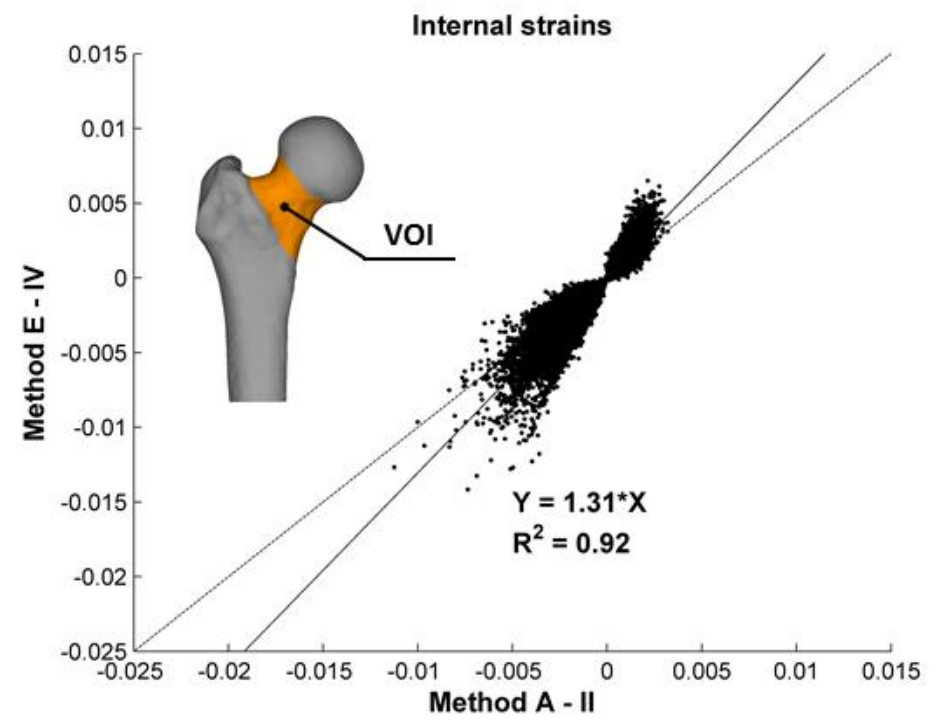




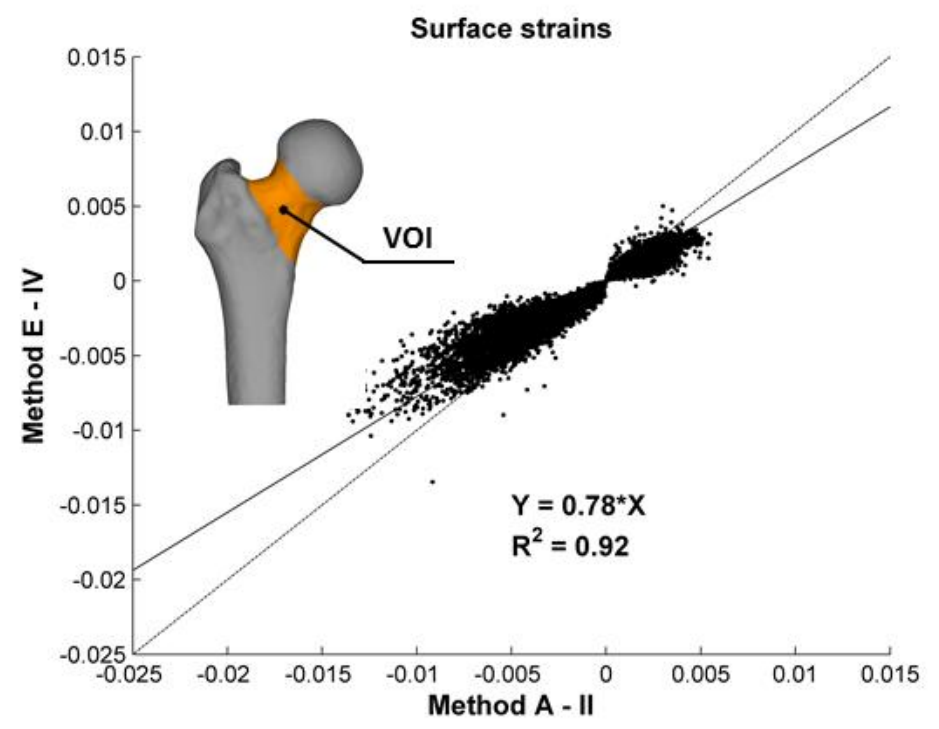

